\title{
Identification and Characterization of the Defensin-Like Gene Family of Grapevine
}

\author{
Lisa Giacomelli, ${ }^{1}$ Valentina Nanni, ${ }^{2}$ Luisa Lenzi, ${ }^{1}$ Jun Zhuang, ${ }^{3}$ Mauro Dalla Serra, ${ }^{4}$ Mark J. Banfield ${ }^{5}$ \\ Christopher D. Town, ${ }^{3}$ Kevin A. T. Silverstein, ${ }^{6}$ Elena Baraldi, ${ }^{2}$ and Claudio Moser ${ }^{1}$ \\ 'IASMA Research and Innovation Centre, Fondazione Edmund Mach, via E. Mach 1, 38010 San Michele all'Adige, (TN), \\ Italy; ${ }^{2}$ DIPROVAL-Criof, University of Bologna, viale Fanin 46, 40127, Bologna Italy; ${ }^{3}$ The J. Craig Venter Institute, 9704 \\ Medical Center Drive, Rockville, MD 20850, U.S.A.; ${ }^{4}$ Institute of Biophysics, National Research Council \& Bruno Kessler \\ Foundation, via alla Cascata 56/C, 38123 Trento, Italy; ${ }^{5}$ Department of Biological Chemistry, John Innes Centre, Colney \\ Lane, Norwich, NR4 7UH, U.K.; ${ }^{6}$ Department of Biostatistics and Bioinformatics, Masonic Cancer Center, University of \\ Minnesota, 425 Delaware Street, SE MMC 806, Minneapolis 55455, U.S.A.
}

Submitted 23 December 2011. Accepted 12 April 2012.

Defensins are a class of small and diverse cysteine-rich proteins found in plants, insects, and vertebrates, which share a common tertiary structure and usually exert broad-spectrum antimicrobial activities. We used a bioinformatic approach to scan the Vitis vinifera genome and identified 79 defensin-like sequences (DEFL) corresponding to 46 genes and allelic variants, plus 33 pseudogenes and gene fragments. Expansion and diversification of grapevine $D E F L$ has occurred after the split from the last common ancestor with the genera Medicago and Arabidopsis. Grapevine DEFL localization on the 'Pinot Noir' genome revealed the presence of several clusters likely evolved through local duplications. By sequencing reverse-transcription polymerase chain reaction products, we could demonstrate the expression of grapevine $D E F L$ with no previously reported record of expression. Many of these genes are predominantly or exclusively expressed in tissues linked to plant reproduction, consistent with findings in other plant species, and some of them accumulated at fruit ripening. The transcripts of five $D E F L$ were also significantly upregulated in tissues infected with Botrytis cinerea, a necrotrophic mold, suggesting a role of these genes in defense against this pathogen. Finally, three novel defensins were discovered among the identified DEFL. They inhibit $B$. cinerea conidia germination when expressed as recombinant proteins.

Innate immunity is an ancient defense system present in most living organisms, including animals, plants, insects, and fungi, and involves nonspecific mechanisms of protection against pathogens. In plants, innate immunity comprises several mechanisms such as systems of fortification of the cell wall, hypersensitive response, and production of antimicrobial substances such as phytoalexins and pathogenesis-related proteins (Sels et al. 2008). Key members of the class of pathogenesis-related proteins are defensins, cysteine-rich peptides (CRP) with antifungal and antibacterial properties, plus additional functions in development (Dresselhaus and Márton 2009;

Corresponding author: C. Moser; E-mail: claudio.moser@iasma.it

* The $\boldsymbol{e}$-Xtra logo stands for "electronic extra" and indicates that seven supplementary figures and three supplementary tables are published online and also that Figure 3 appears in color online.
Lay and Anderson 2005). Plant defensins were originally described as members of small multigene families; this assertion was then disputed by the discovery of over 90 defensin-like sequence genes (DEFL) in rice and more than 300 members in Arabidopsis thaliana and legumes (Graham et al. 2004; Silverstein et al. 2005, 2007). Though usually diverse in their primary sequence, DEFL display conserved cysteine residues arranged into disulfide bonds, which stabilize their structure. The classical structure comprises eight conserved cysteine residues engaged in four disulfide bonds, but defensins with 10 cysteine residues have been identified in petunia and tobacco (Lay et al. 2003). Moreover, plant DEFL are small CRP (45 to 54 amino acids), usually basic in their mature form and targeted to the secretory pathway by a more acidic N-terminal signal peptide (Carvalho and Gomes 2009). Defensin-encoding genes are generally structured as two exons of conserved size and an intron of variable length; the first exon usually encodes entirely for the signal peptide, whereas the second exon contains the cysteine-rich portion.

In plants, antimicrobial peptides provide a barrier against a broad range of pathogens, especially in tissues important for reproduction such as seeds, flowers, and fruit, which become more prone to pathogen attack with the progression of fruit softening and sugar accumulation. The majority of plant DEFL identified thus far were, indeed, isolated from seeds and floral organs (Dos Santos et al. 2010; Janssen et al. 2003; Kovalchuk et al. 2009; Lay et al. 2003; Tregear et al. 2002) and often display in vitro the ability to inhibit the growth of a large spectrum of fungi (Lay and Anderson 2005). Though an in vivo role in plant defense response has to be further confirmed, additional evidence of this possibility comes from the reported inducibility of several plant $D E F L$ by microbial pathogens (Penninckx et al. 1996; Terras et al. 1995; Zimmerli et al. 2004) and by the augmented disease resistance displayed by transgenic plants overexpressing heterologous DEFL (Gao et al. 2000; Terras et al. 1995).

Despite the abundance of genomic sequence information in grapevine (Vitis vinifera L.) (Jaillon et al. 2007; Velasco et al. 2007), little is yet known about the genes encoding for antimicrobial peptides in this crop (de Beer and Vivier 2008). In this work, which represents the first attempt for a woody species, we set out to systematically identify small $D E F L$ genes in the grapevine genome, analyze their gene structure, and determine the expression of a large group of the identified sequences in 
different tissues. In order to address their role in defense, we studied their expression in tissues infected by two fungal pathogens of grape, Plasmopara viticola and Botrytis cinerea. Moreover, we discovered three novel grapevine defensin genes by testing the effect of the corresponding recombinant proteins on conidia germination in vitro.

The identification of a large group of grapevine sequences, which are likely involved in the response to biotic and abiotic stresses, provides new opportunities for the improvement of this world-wide important crop.

In addition, due to their broad range of antimicrobial activity, stability, and low cytotoxicity in humans, plant defensins are suitable candidates for therapeutic applications (Thevissen et al. 2007).

\section{RESULTS}

Genome-wide identification of putative defensin sequences.

In this work, an accurate scan of the grape genome ( $V$. vinifera L. 'Pinot Noir', clone ENTAV115) (Velasco et al. 2007) was performed using successive iterations of hidden Markov model (HMM) and BLAST searches to identify small, secreted DEFL. Toward this goal, grapevine genomic sequences were scanned with a set of HMM generated from sequences identified in earlier work (Graham et al. 2004; Silverstein et al. 2007). Additional genes that were not predicted by this procedure were discovered through successive BLAST searches on the genome sequence using the discovered set of $D E F L$ as a query. In total, $79 D E F L$ were identified, numbered from 1 to 79. They consist of 46 genes or allelic variants, nine likely pseudogenes, and 24 gene fragments. The complete list of predicted genes, pseudogenes, and fragments is reported in Supplementary Table S1, including their nucleotide and amino acid sequences and CRP class (Silverstein et al. 2007). Although they share high nucleotide identity with DEFL genes, pseudogenes are either truncated by premature stop codons, affected by frame shifts in the DEFL domain, or lack predicted splicing sites. DEFL fragments consist of gene sequences with missing or unknown start codons. Their presence can indicate either a mutation event (e.g., an incomplete duplication) or the lack of information on the $5^{\prime}$ end of the gene, possibly due to their localization close to the edge of a genomic contig.

\section{Primary sequence analysis.}

Considering their cysteine signatures, the identified grape DEFL were divided in four groups (Fig. 1). Although the sequences included in groups 1 and 3 share low intragroup similarity, they all feature a conserved pattern of cysteine residues. Sequences of group 2 are the most abundant and are extremely conserved. All the other identified DEFL are highly heterogeneous and, with exclusion of the cysteine stabilized CS $\alpha \beta$ motif (Cornet et al. 1995; Zhu et al. 2005), lack any peculiar cysteine hallmark arrangement. They were all grouped in a fourth additional DEFL group.

With the exception of gene fragments, all sequences in group 1 translate into peptides containing the distinctive $\operatorname{CS} \alpha \beta$ and $\gamma$-core motif and a predicted signal peptide positioned at their N-terminus. These sequences display a number of cysteine residues in the mature protein varying from 8 to 10 , and a $\mathrm{CX}_{3-14} \mathrm{CX}_{4-5} \mathrm{CX}_{3} \mathrm{CX}_{8-11} \mathrm{CX}_{5-10} \mathrm{CCC}$ pattern. DEFL 1 and 2 and pseudogene 3 likely represent three different loci rather than allelic variants, because they matched three different regions when blasted against the genome of the quasi homozygous genotype PN40024 (Jaillon et al. 2007) (Supplementary Table S2). Interestingly, $D E F L 6,7$, and 8 encode for three very similar peptides, with a calculated isoelectric point $(\mathrm{pI})$ value between 3.7 and 4.7, which is rather acidic compared with the majority of the other grape DEFL (pI approximately 8) (Supplementary Fig. S1).

Group 2 includes 13 translated $D E F L$ gene sequences. These consist of highly conserved basic peptides, containing 9 or 10 cysteine residues arranged in $\operatorname{CS} \alpha \beta$ and $\gamma$-core motif (Fig. 1). All DEFL included in this group share a the typical cysteine pattern, $\mathrm{CCX}_{8} \mathrm{CX}_{12-13} \mathrm{CX}_{3} \mathrm{CX}_{3} \mathrm{CX}_{5} \mathrm{CX}_{8-9} \mathrm{CHCYC}$, with the exception of DEFL 18 and 67, lacking the last cysteine residue.

On the basis of sequence similarity, two subgroups are identified in group 2: the first one, subgroup 2-1, comprises the DEFL 13 to $19,41,42,73$, and 74; the second, subgroup 2-2, consists of DEFL 21 and 67. These DEFL share over $90 \%$ of peptide sequence identity within each subgroup and over $67 \%$ between the two. In addition, eight pseudogenes and one fragment were ascribed to this group on the basis of their sequence similarity. Many of these pseudogenes encode a methionine in place of a lysine residue right at the beginning of the $\mathrm{C}$-terminal cysteine-rich motif and downstream to the stop codons or frame shifts.

Group 3 collects sequences displaying the $\mathrm{C}$-terminal conserved cysteine pattern $\mathrm{CX}_{5-10} \mathrm{CX}_{4-6} \mathrm{CX}_{3} \mathrm{CX}_{9-15} \mathrm{CX}_{5-12} \mathrm{CXCX}_{3} \mathrm{C}$, all containing the $\mathrm{CS} \alpha \beta$ signature. Group 3 includes the $V$. vinifera antimicrobial peptide $1(V v$-Ampl), which is the only grapevine defensin gene characterized thus far (de Beer and Vivier 2008). The $V v$-Ampl sequence matches two contigs on the 'Pinot Noir' genome of the clone ENTAV115 (Velasco et al. 2007).

Finally, $9 D E F L$ genes and 11 fragments were ascribed to the additional group (Fig. 1). Among these, DEFL 53 is a oneexon predicted gene lacking the typical signal peptide coding sequence and translating in a long acidic peptide of 111 amino acids with 18 cysteine residues, which display both the CS $\alpha \beta$ and the $\gamma$-core signatures. Nevertheless, its expression was not detected. DEFL 33 is an expressed gene that translates also in a long defensin peptide (114 amino acids) with 12 cysteine residues.

\section{Phylogenetic analysis.}

An attempt was made to cluster all 79 grapevine DEFL nucleotide sequences with the aim of establishing the phylogenetic relationships among them; however, a master alignment of the entire family (a prerequisite for accurate tree building) proved to be impossible due to the great divergence among many of the sequences. The clustering procedure did reveal four large clusters that consisted of at least four grapevine $D E F L$ each. Upon subsequent reclustering of these groups with all Arabidopsis and Medicago DEFL, we ended up with four homologous groups that included members from each of these three species, whose sequences could be reliably aligned for subsequent phylogenetic inference. Trees produced from MrBayes are shown in Figure 2 for each of these four groups. Posterior probabilities supporting each node were very high, as displayed in the tree, and the topology and branch lengths for all four trees were nearly identical to trees produced by the neighbor-joining algorithm (data not shown), providing strong confidence in the accuracy of the phylogenetic analysis. Of the four groups, only one (Fig. 2C) had comparable homologs in Medicago spp. All but one group (Fig. 2B) had identifiable homologs in Arabidopsis. In all cases, grapevine, Medicago, and Arabidopsis DEFL separated into distinct clades according to species, with perfect support (i.e., 1.0) from posterior probabilities.

Genomic organization of the $V$. vinifera $D E F L$ gene family.

In all, 75 of the 79 DEFL were assigned a chromosomal location on 15 of the $19 \mathrm{~V}$. vinifera chromosomes of 'Pinot Noir' 
clone ENTAV115 (Fig. 3A), whereas DEFL 19 and 37 and fragments 49 and 63 were assigned to two scaffolds still unlinked to any specific chromosome.

With the exception of the highly similar sequences of group 2, DEFL belonging to the same group are spread on different chromosomes either singularly or as clusters composed of a variable number of $D E F L$. The majority of group 2 sequences appeared clustered on chromosome 10 (19 sequences) of the ENTAV115 genome, indicating the occurrence of strong local gene duplication (Fig. 3A and B).

\section{Group 1: $\mathrm{CX}_{3-14} \mathrm{CX}_{4-5} \mathrm{CX}_{3} \mathrm{CX}_{8-11} \mathrm{CX}_{5-10} \mathrm{CCC}$}

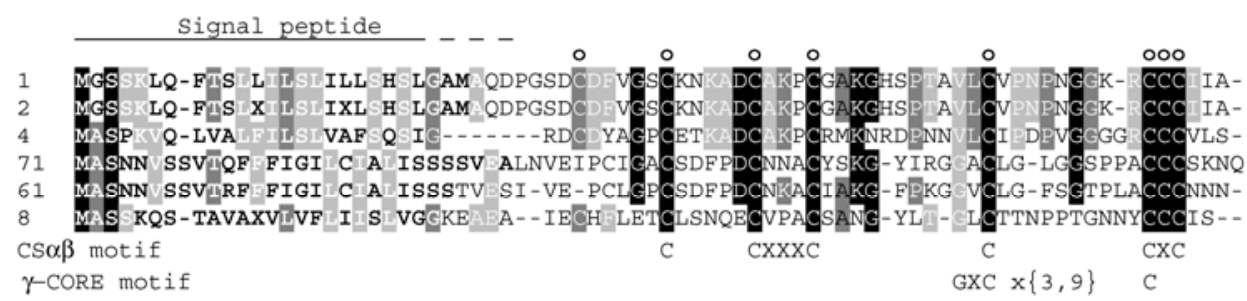

Group 2: $\mathrm{CCX}_{8} \mathrm{CX}_{12-13} \mathrm{CX}_{3} \mathrm{CX}_{3} \mathrm{CX}_{5} \mathrm{CX}_{8-9} \mathrm{CHCYC}$ and similar
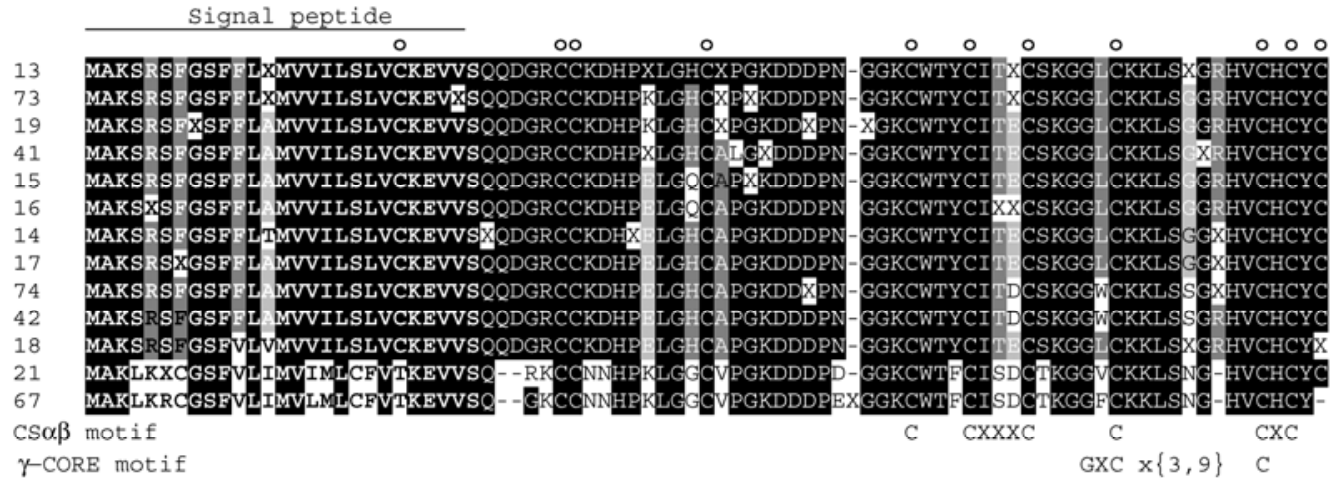

Group 3: $\mathrm{CX}_{5-10} \mathrm{CX}_{4-6} \mathrm{CX}_{3} \mathrm{CX}_{9-15} \mathrm{CX}_{5-12} \mathrm{CXCX}_{3} \mathrm{C}$
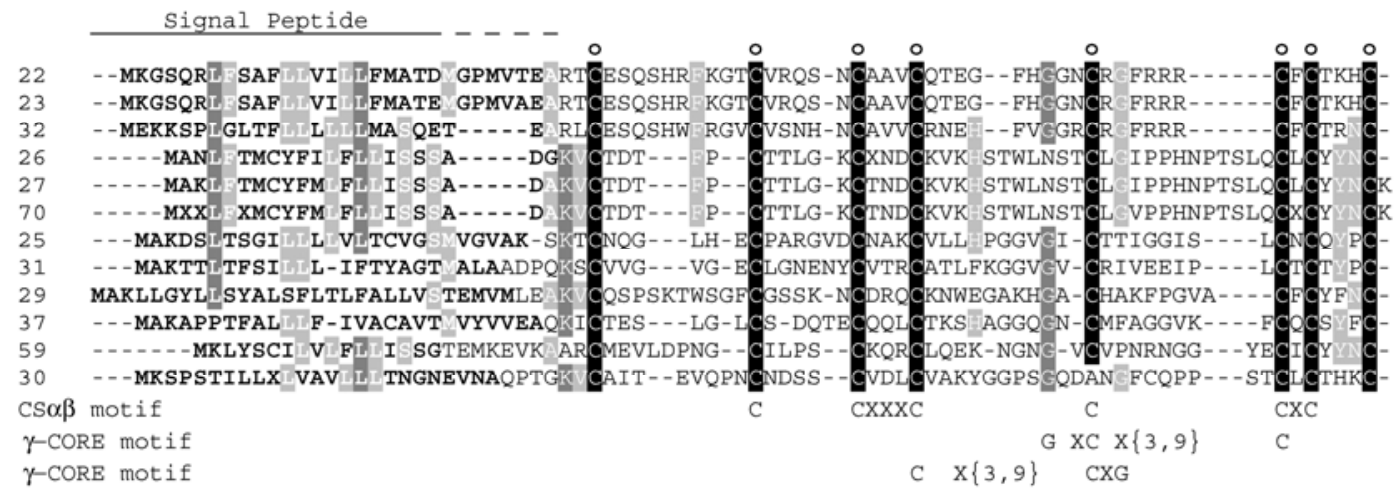

\section{Additional group}

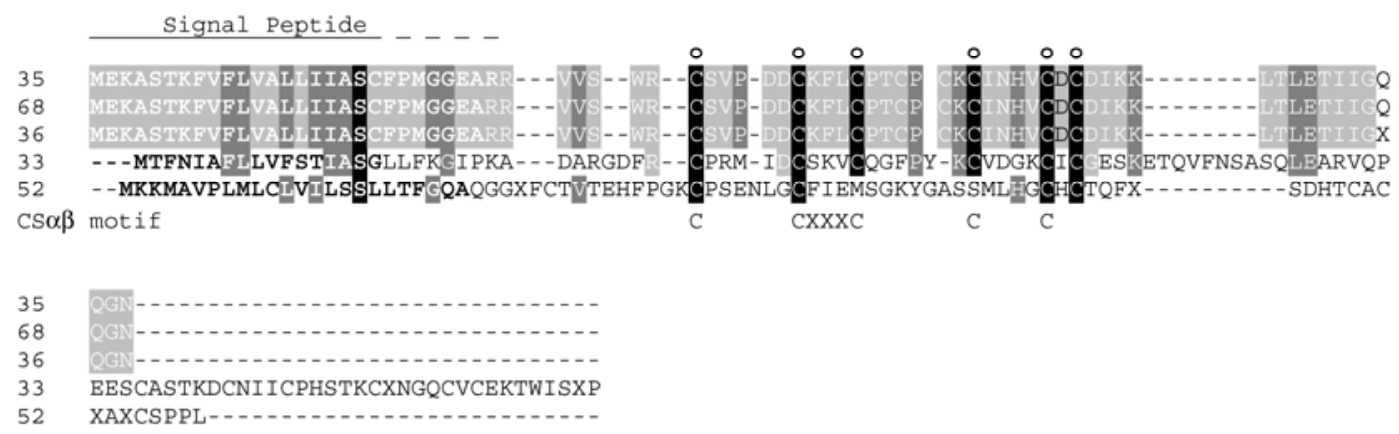

Fig. 1. Multiple sequence alignments of grapevine defensin-like sequences (DEFL) according to their cysteine signature. Alignment of the grapevine DEFL for which expression of the corresponding transcript has been verified in this work. Sequences were classified in three groups according to the specific cysteine's pattern. Additional group include all the other DEFL which did not fall in groups 1 to 3 . The position of conserved cysteine residues is indicated by small circles above the alignments. Uncertain amino acids (possibly due to single nucleotide proteins) are indicated by Xs. Sequence similarity is highlighted by different gray shades, lighter for low similarity, up to black for amino acid identity. The signal peptide predicted with Signal P is indicated in bold. 
Many identified DEFL share high nucleotide identity and are located in close proximity on the grapevine genome, opening the possibility that they may correspond to alleles of the same locus rather than to distinct loci. In order to obtain insights on this matter, the genome of the quasi-homozygous genotype PN40024 (Jaillon et al. 2007) was scored for corresponding DEFL. A similar number of distinct loci was found on the PN40024 by BLAST search when using the identified $D E F L$ as queries, suggesting that most sequences are distinct loci rather than alleles. This is not the case of DEFL 22 and 23 corresponding to $V v-A M P 1$, which are assembled in tandem on chromosome 1 on the 'Pinot Noir' genome of the clone ENTAV115, but this sequence is found only once in the 'Pinot Noir' genome of the clone PN40024.

The observed genomic distribution is likely the result of recent tandem duplications because, in all cases where a cluster of two or more $D E F L$ is present, those sequences are often almost identical. However, duplication events to distant positions via segmental duplication of entire chromosomal regions or via ectopic duplication of smaller regions cannot be excluded.

The presence of transposons of almost identical sequence in multiple positions of a genome promotes recombination and genome restructuring, and they are considered to have a spe- cial role in plant genome evolution (Bertioli et al. 2009). For this reason, we have investigated the presence of repetitive elements in the largest $D E F L$ clusters that were identified. This was the case for the large cluster of $D E F L$ of group 2 localized on chromosome 10 and for a smaller cluster where a large number of transposable elements, preferentially retro elements of the Copia and Athila type (Feschotte et al. 2002), were found interspersed (Fig. 3B).

\section{DEFL gene structure.}

To determine $D E F L$ gene structure, we carried out $5^{\prime}$-rapid amplification of cDNA ends (RACE) experiments and amplification from cDNA with intron spanning primers followed by sequencing. The structure of grapevine DEFL genes is illustrated in Supplementary Figure S2. Most $V$. vinifera $D E F L$ genes share the typical exon-intron-exon structure, in which the first exon (average size $62 \mathrm{bp}$ ) encodes the signal peptide and the second one (average size $180 \mathrm{bp}$ ) contains the cysteine-rich DEFL signature.

Except for $D E F L 4,10,61$, and 71 which contain a longer intron, $D E F L$ genes of group 1 typically contain a small intron of approximately $100 \mathrm{bp}$. DEFL of group 2 were very homogeneous in terms of gene structure, consistent with the hypoth-

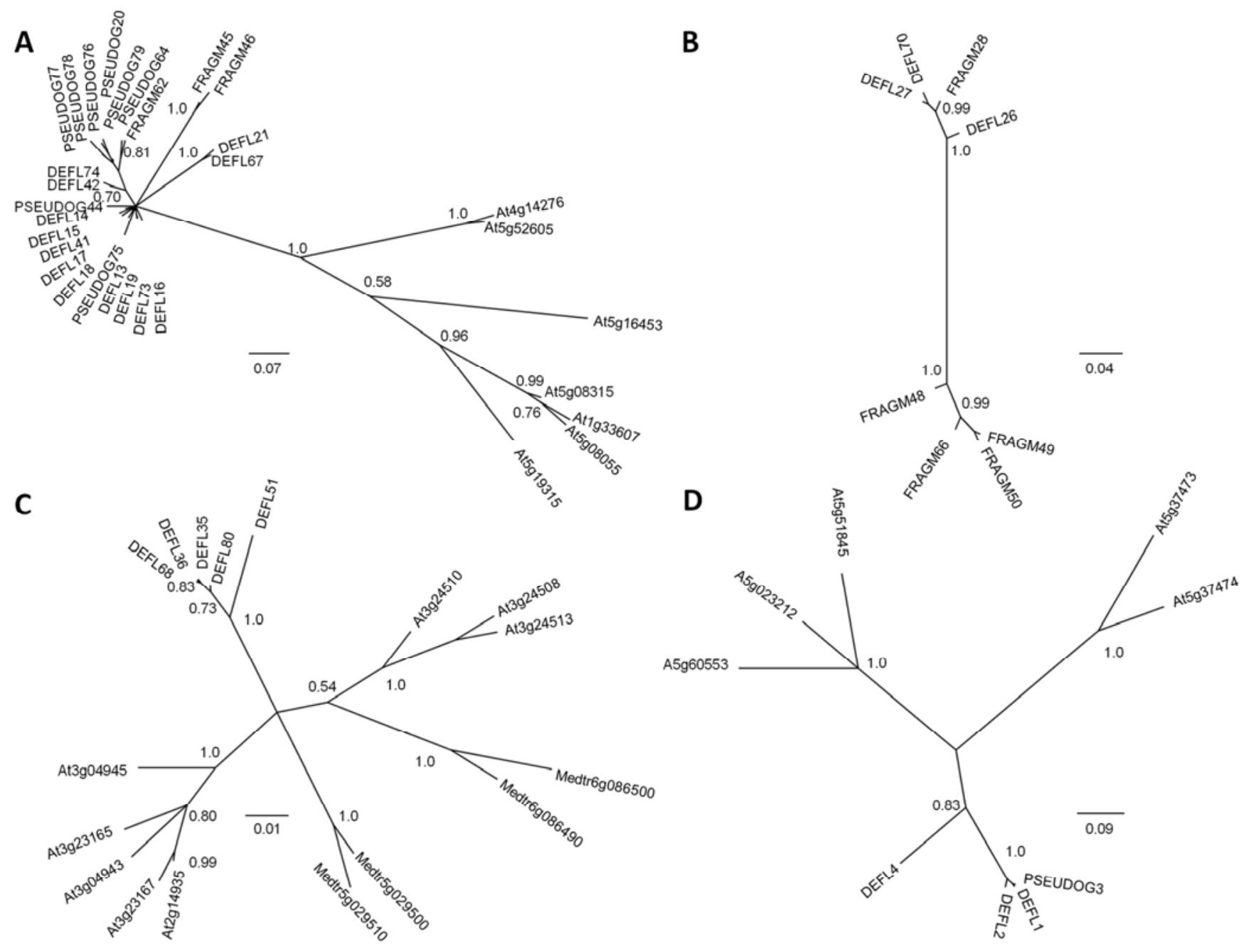

Fig. 2. Phylogenetic trees of the four largest grapevine defensin-like (DEFL) paralogous gene clusters with the nearest homologs from Arabidopsis and Medicago spp. A, Largest DEFL cluster corresponding to group 2 (cysteine-rich protein CRP0220) (Silverstein et al. 2007). B, Novel DEFL cluster with no close homolog from either Arabidopsis or Medicago spp. C, DEFL cluster most closely related to groups CRP0680 and CRP0920 in Arabidopsis and Medicago spp. D, DEFL cluster related to Arabidopsis groups CRP0960 and CRP0980. Trees were constructed using MrBayes (Ronquist and Huelsenbeck 2003) on multiple sequence alignments that were aligned with PRANK (Löytynoja and Goldman 2010) and purged of gaps and ambiguous columns. Posterior probabilities for nodes with greater than $50 \%$ likelihood are indicated. 
esis of their origin based on recent duplication. The structures of genes of subgroups 2-1 and 2-2 were inferred by similarity with 'Cabernet Sauvignon' expressed sequence tag (EST) sequences (EC980275 and EC987327, respectively) and were experimentally confirmed. Group $3 D E F L$ greatly vary in terms of gene structure: the intron length ranges from 84 to $994 \mathrm{bp}$, whereas exon sizes are fairly conserved (average size of 50 and $180 \mathrm{bp}$ for the first and second exon, respectively). DEFL 22 and 23 are two allelic variants of the same gene encoding defensin $V v$-AMPl. In fact, no single nucleotide proteins (SNP) were found after resequencing over $3 \mathrm{~kb}$ of the encompassing region on the two contigs identified on the ENTAV115 'Pinot Noir' genome, whereas an average of one SNP every $100 \mathrm{bp}$ is generally found in the coding sequences of grapevine (Velasco et al. 2007). DEFL 29 gene structure remains uncertain because amplification of its cDNA from different tissues and genotypes always led to an intron-retaining sequence. This may suggest that DEFL 29 is either not a defensin or represents a case of alternative splicing, as reported for many plant resistance genes (Gassmann et al. 1999; Jordan et al. 2002; Lawrence et al. 1995; Moran et al. 2008; Schornack et al. 2004). Consistent with its high diversity in sequences, the additional group of $D E F L$ includes highly heterogeneous gene structures and many fragments.

\section{$D E F L$ gene expression in different $V$. vinifera tissues.}

The expression of at least 24 sequences or groups of highly similar sequences was detected in different tissues. Of these, 16 did not match to any $V$. vinifera EST and had no previous record of expression. A summary of this result is depicted in column E (expressed) of Supplementary Figure S3. Several of these sequences are not expressed, supporting the hypothesis that they are fragments (i.e., DEFL 34, 81, 63, 57, and 58). On the other hand, DEFL fragments $40,60,55 / 72$, and $56 / 65$ were amplified from cDNA. These fragments are either part of genes with an unknown $5^{\prime}$ end or genes that do not encode DEFL proteins.

Because it has been reported that DEFL often display tissue specificity, we further investigated this issue by quantitatively measuring the expression of those genes which were found to be expressed in the qualitative analysis (Fig. 4).

Many of the analyzed $D E F L$ showed tissue specificity: $D E F L$ 31,61 , and 71 are detected only in immature seeds (at 2 weeks

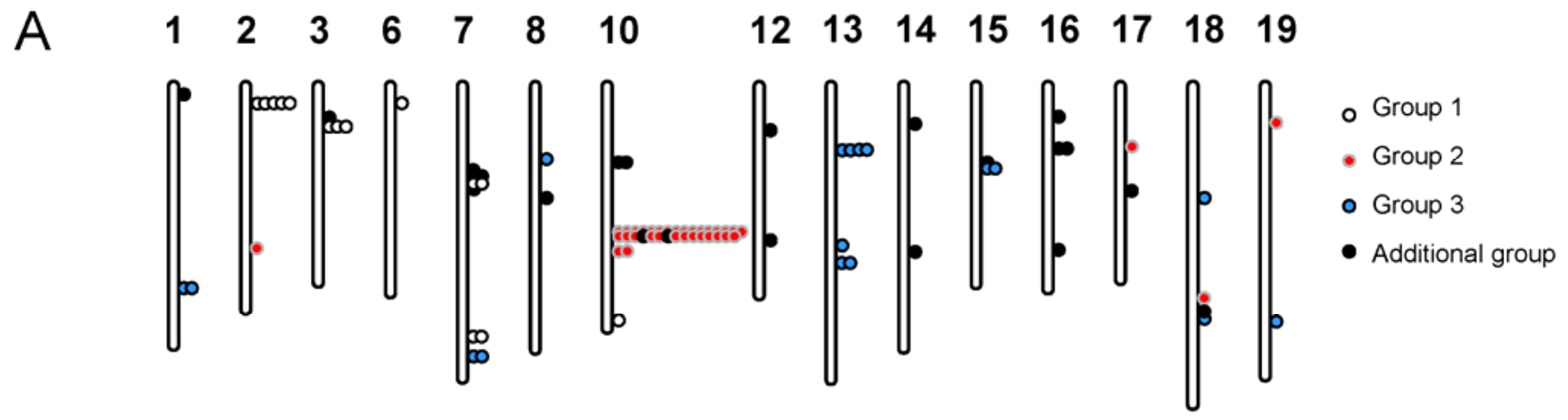

B Cluster of group 2 DEFL onto chromosome 10

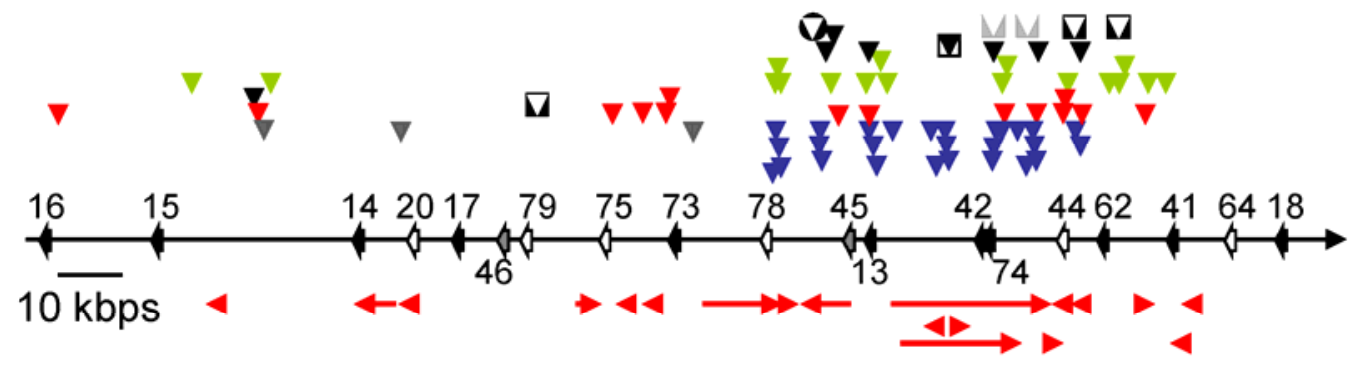

Region around DEFL 35 and 36 onto chromosome 7
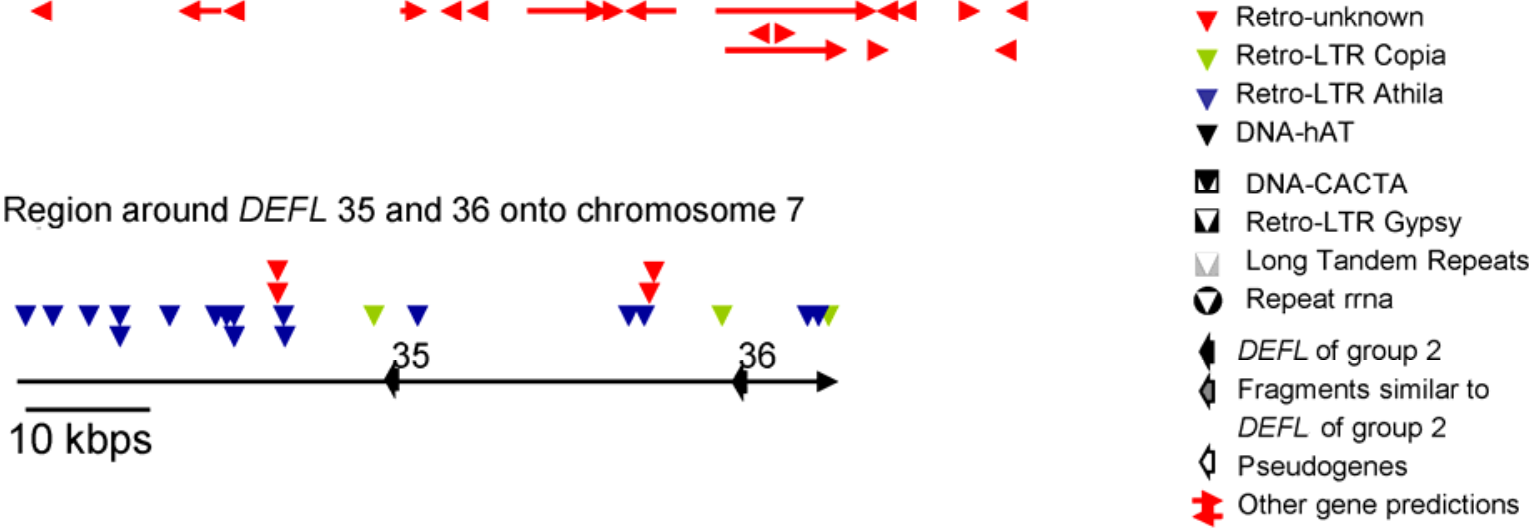

Fig. 3. Genomic organization and gene structure of defensin-like sequences (DEFL). A, Localization of DEFL on 15 of the 19 chromosomes of Vitis vinifera 'Pinot Noir' ENTAV115. Chromosomes are represented by vertical bars, whereas DEFL are represented by circles of different shades according to their grouping. Chromosomes with no DEFL are not shown. B, Cluster of group 2 DEFL on chromosome 10 and region around DEFL 35 and 36 on chromosome 7. Chromosomal segments are represented by thin black arrows on which are interspersed $D E F L$ represented by black and gray arrows and identified by numbers. Pseudogenes are indicated by asterisks, and arrows denote additional gene predictions. Downward pointing triangles represent transposable elements, with type indicated by different shades as indicated in the lower right side of the figure and which start coordinate on the chromosome indicated by the triangle apices. 
prior to véraison), whereas $D E F L 30,32$, and 33 were predominant in seeds but detected also in a few other tissues. In particular, expression of DEFL 32 was approximately 450-fold higher in seeds at véraison $\left(\mathrm{Se}_{2}\right)$ than in other tissues and also higher than the expression of DEFL 30 when the two genes were analyzed in the same quantitative polymerase chain reaction (qPCR) experiment (data not shown).

DEFL 59 and the subgroup 2-1 (14 sequences of group 2 that share over $85 \%$ nucleotide identity) appeared to be largely predominant in inflorescence. Their expression was also detected at a low level in fruit (less than 100- and 250-fold for DEFL 59 and subgroup 2-1, respectively) but not in roots and leaves. A major expression in inflorescence and seed tissues was also observed for a sequence matching to DEFL 1 and 2 (Fig. 4).
When compared, the expression of DEFL of subgroup 2-1 in inflorescence appeared much higher than that of $D E F L 1 / 2$; however, this could be explained by the high number of copies in subgroup 2-1. The expression of the two allelic forms of $V v$ $A M P 1, D E F L 22$ and 23, was selectively determined by using discriminating primers: both alleles are expressed in all examined tissues and accumulated with ripening in mesocarp and exocarp as well. DEFL 22 was predominant in seed compared with DEFL 23.

Interestingly, fragments 40 and 55/72 were amplified in all analyzed tissues and are relatively abundant. DEFL 29 was also abundantly expressed in all tissues but inflorescence.

The expression of six additional sequences (DEFL 8,21, 26, 34,52 , and 56/65) was lower than the qPCR detection limit;
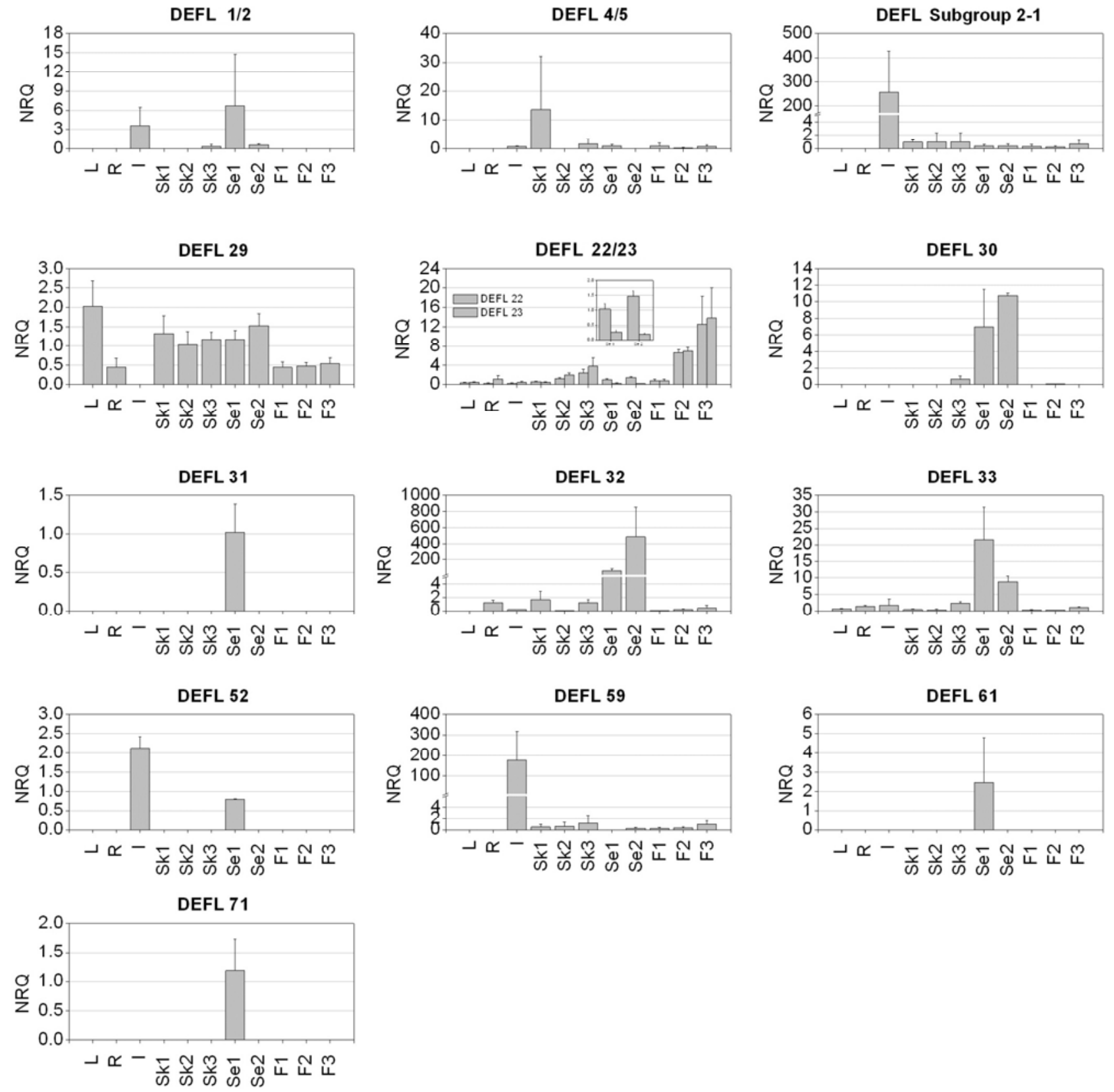

Fig. 4. Quantitative expression of defensin-like sequences $(D E F L)$ in different tissues and at three fruit developmental stages. $D E F L$ expression was analyzed by real time polymerase chain reaction in 11 different tissues: $\mathrm{L}=$ fully developed leaves; $\mathrm{R}=$ roots; $\mathrm{I}=$ inflorescences at anthesis; $\mathrm{SK}$, Se, and $\mathrm{F}=$ grape skin, seed, and flesh, respectively, at the ripening stages indicated by digits, where $1=2$ weeks prior to véraison, $2=$ at véraison, and $3=2$ weeks after véraison. Vertical bars represent the averages of normalized relative quantities (NRQ) considering three independent biological replicates with their standard deviations $(n=3)$. If expression was detected in one biological replicate only, the respective NRQ was discarded. In this analysis, NRQ were obtained by normalization with the expression of ACTIN and GAPDH, which were the two most stable genes among six housekeeping genes in the analyzed tissues. 
however, their amplification from cDNA and sequencing indicated that they are expressed.

Involvement of $V$. vinifera $D E F L$ in plant defense.

In order to elucidate the possible role in plant defense of the identified grapevine $D E F L$, we investigated their expression induction in tissues challenged with $P$. viticola and $B$. cinerea, which are the causal agents of grapevine downy mildew and gray rot, respectively. Although the tissue expression study clearly showed that most DEFL are expressed in a tissue-specific manner, we decided to carry out the qPCR analysis in the infected tissues (leaf and berry, exocarp and mesocarp, and inflorescence) with the same primers used in the tissue expression analysis, to test whether some genes that are not expressed in normal conditions are, instead, expressed upon fungal infection.

Our results suggested that no major induction occurs in the leaves of young 'Pinot Noir' plants infected with $P$. viticola (Supplementary Fig. S4). Among the 24 sequences or groups of highly similar sequences analyzed by qPCR, only 6 were expressed in the control and treatment samples at a quantifiable level (DEFL 22, 23, and 33 and fragments 29, 40, and
A
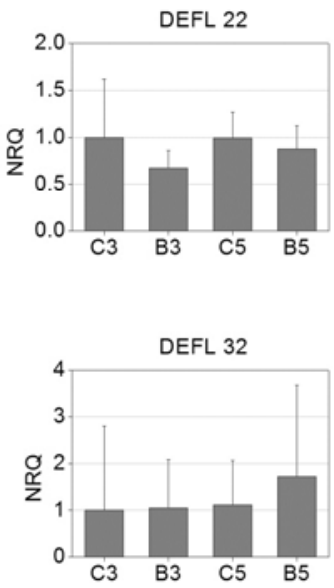
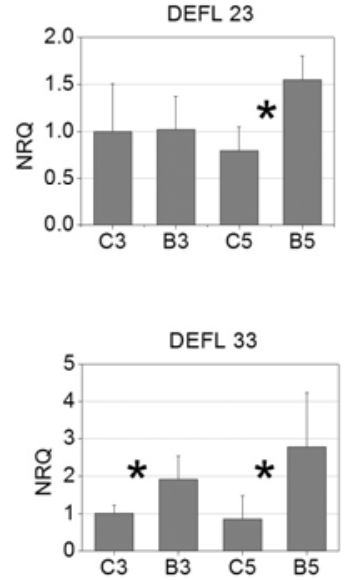
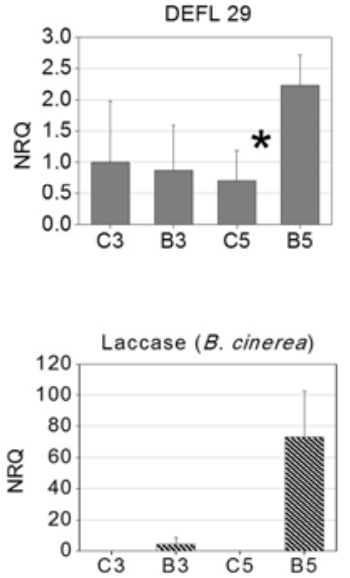

B
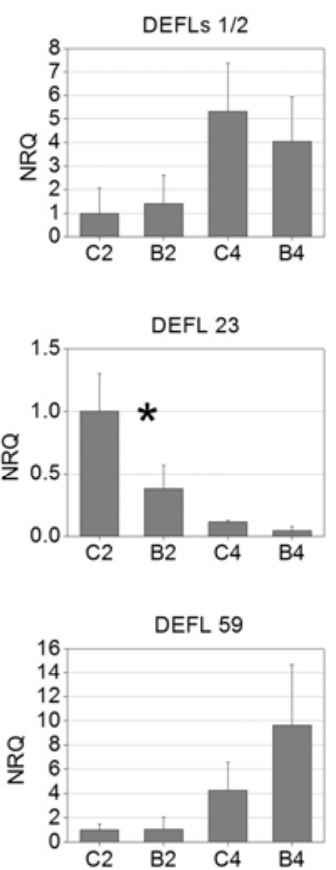
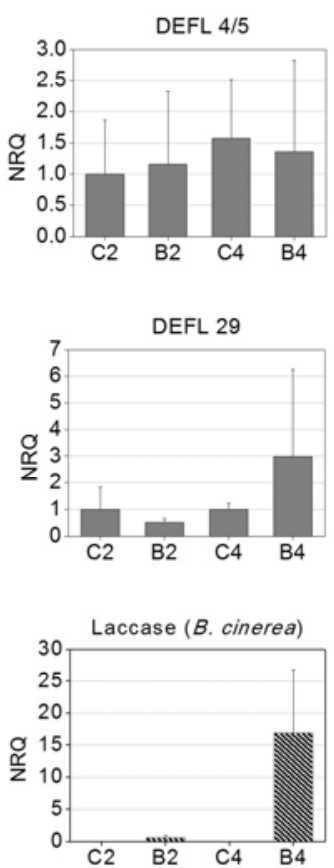
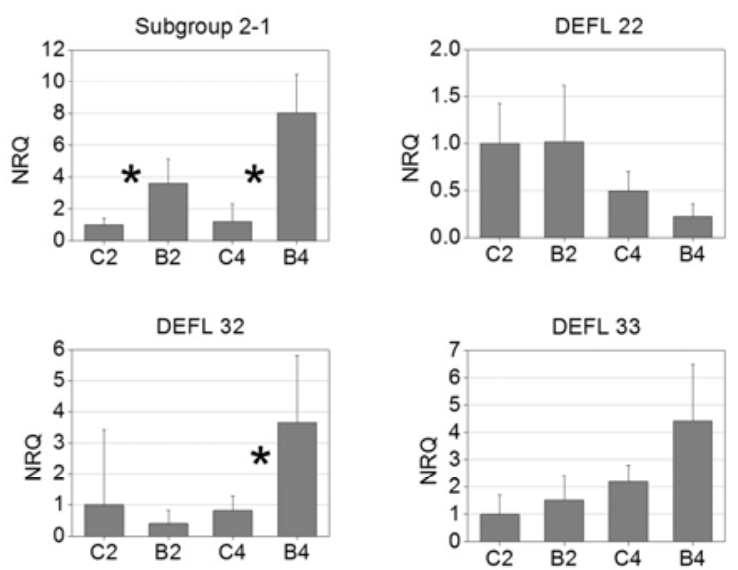

Fig. 5. Relative expression of defensin-like sequences $(D E F L)$ in tissues infected by Botrytis cinerea. A, Expression of $D E F L$ in grape berries infected with B. cinerea. Plots represent quantitative polymerase chain reaction (qPCR) quantitation analysis of the expression of $D E F L 22,23,29,32$, and 33 , and a $B$. $c i$ nerea-specific gene (laccase). Analyzed tissues were control (C) and Botrytis-infected berries (exocarp and mesocarp) (B) at 3 and 5 days postinfection (dpi). Vertical bars represent average relative quantities normalized for expression of $G A P D H$ and $E F 1 \alpha$. Error bars: standard deviations $(\mathrm{C}$ at 3 dpi, $n=5$ or 6 ; $\mathrm{C}$ at $5 \mathrm{dpi}, n=5$; B at 3 and $5 \mathrm{dpi}, n=4)$. DEFL 31, 59, and subgroup 2-1 were also analyzed but were amplified in neither control nor infected grape berries. For simplicity, normalized relative quantities (NRQ) of control at 3 dpi (C3) was set to one. B, Expression of $D E F L$ in inflorescences infected with $B$. $c i$ nerea. Plots represent qPCR quantitation analysis of the expression of DEFL 1/2, 4/5, subgroup 2-1, 22, 23, 29, 32, 33, and 59, and a B. cinerea-specific gene (laccase). Analyzed tissues were control (C) and Botrytis-infected inflorescences (B) at 2 and 4 dpi. Seed-specific DEFL 31 was not amplified in the control or in infected inflorescences. For simplicity, NRQ of control at 2 dpi (C2) was set to one. Vertical bars represent average relative quantities normalized for expression of $A C T I N, T U B U L I N$, and EF $1 \alpha$. Error bars: standard deviations (C at 2 dpi, B at 2 dpi, and B at 4 dpi, $n=7$; C at 4 dpi, $n=3$ ). Asterisks indicate those changes in the comparison between treated and control samples at a given time point that are significant, with a probability of error smaller than $5 \%$ in a Student' $s t$ test performed on the $\log _{2}(\mathrm{RQ})$. 
55/72) and no significant differences were observed in infected tissues compared with the controls. However, several $D E F L$ genes appeared upregulated upon infection with $B$. cinerea when tested in fruit and inflorescence: tissues where they are predominantly expressed and preferred by Botrytis infection (Fig. 5).

Preliminary results obtained on a ripe cluster of 'Pinot Noir' naturally and heavily infected by gray rot showed that $D E F L$ 32 and 33 were likely induced by Botrytis spp. (not shown). Therefore, the experiment was repeated with multiple biological replicates infecting (under laboratory conditions) grape clusters harvested from the vineyard. We found three $D E F L$ that were significantly induced within 5 days upon infection: DEFL 23, 29, and 33 (Fig. 5A). For the latter, an early induction was seen already at 3 days postinfection, whereas $D E F L$ 23 and 29 were induced later. Interestingly, DEFL 22 does not seem to be induced, in contrast to its allelic form, DEFL 23. Expression of DEFL 1/2, 4/5, 30, 31, and 61 was also evaluated and they were not detected in infected or control tissues.

In an analogous experiment, we compared $D E F L$ expression in 'Pinot Noir' inflorescences infected with a suspension of $B$. cinerea conidia versus control inflorescences, and the results are reported in Figure 5B. Mycelium development was macroscopically observed already after 24 h. Botrytis spp.-mediated induction was observed for genes expressed predominantly in inflorescence and seed in the tissue expression analysis (Fig. 4). The inflorescence specific genes of subgroup 2-1 showed an
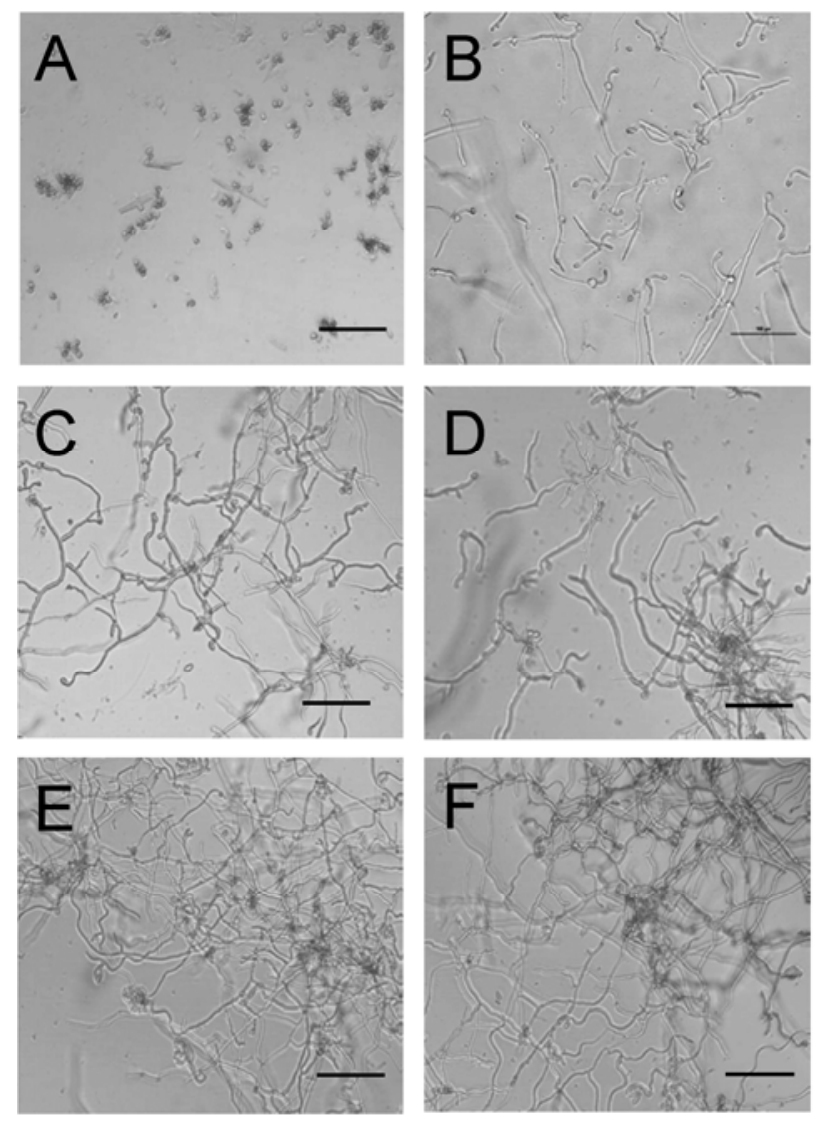

Fig. 6. Inhibition of Botrytis cinerea conidia germination in the presence of recombinant defensin-like (DEFL) proteins. Pictures show developing mycelium of $B$. cinerea in a medium supplemented with recombinant proteins or buffer at $50 \mu \mathrm{g} / \mathrm{ml}$ : A, DEFL 13; B, DEFL 22 (Vv-AMP1); C, DEFL 31; D, DEFL 59; E, buffer; and F, reduced and alkylated DEFL 13. Negative results similar to those in $\mathrm{F}$ were obtained for the reduced and alkylated forms of DEFL 22, 31, and 59. Bar $=100 \mu \mathrm{m}$. Images were taken after $16 \mathrm{~h}$ of incubation at $20^{\circ} \mathrm{C}$. early and significant upregulation already at 2 days postinfection, whereas $D E F L 32$, predominant in seeds, was significantly induced only after 4 days. In addition, DEFL 29, 33, and 59 are likely induced at 4 days postinfection, although those changes were not statistically significant when considering a probability of error smaller than $5 \%$. No induction was observed for DEFL $1 / 2,4 / 5,22$, and 23, and expression of $D E F L$ 31 and 60 was below the detection limit (not shown).

Contrary to what was observed in berries, DEFL 23 is downregulated in infected inflorescences at 2 days postinfection, whereas the transcript of its allelic form, DEFL 22, doesn't change. We also observed that the expression of $V v-A M P 1$ decreases over time in the control inflorescences as well as in the infected ones but not in berries.

Among the DEFL genes induced either in inflorescences or in grapes following Botrytis infection, we were able to test the antimicrobial activities of DEFL 13 (subgroup 2-1), 22/23 (Vv$A M P 1$ ), and 59 (group 3). In addition, we tested DEFL 31, for which expression is seed and stage specific. Each of these DEFL was produced using Escherichia coli as a heterologous expression host and purified to homogeneity. DEFL 22 was expressed as a thioredoxin (TRX) fusion protein (Supplementary Fig. S5A) and DEFL 13, 31, and 59 were expressed as maltose-binding protein (MBP) fusions. Previous attempts to express these proteins in either untagged or histidine (His)-tag forms were not successful.

The microscope analysis of the growth and germination of $B$. cinerea conidia incubated with the purified proteins showed that all four DEFL significantly inhibited conidia germination and mycelial growth after $24 \mathrm{~h}$, though to different extents (Fig. 6). The mycelium showed no apparent alteration of hyphal morphology with respect to the untreated fungal culture. Antifungal activity was confirmed by calculation of $\mathrm{IC}_{50}$ (half maximal inhibitory concentration) values, determined using a spectrophotometric assay, $60 \mathrm{~h}$ after addition of DEFL to the conidia (Table 1). The $\mathrm{IC}_{50}$ values of the four DEFL were 5.3 to $50 \mu \mathrm{g} / \mathrm{ml}$, with DEFL 13 as the strongest inhibitor. These values are in the same order of magnitude previously reported for Vv-AMP1 (13 $\mu \mathrm{g} / \mathrm{ml})$ (de Beer and Vivier 2008).

When the incubation experiments were repeated using reduced and alkylated forms of the recombinant proteins, no significant difference in fungal growth compared with the negative control was observed (Fig. 6). This indicates that the antimicrobial activity is strictly dependent on the oxidized form of the proteins and that intramolecular disulfide bridges play a crucial role for protein activity.

\section{DISCUSSION}

\section{$D E F L$ identification.}

The family of $D E F L$ genes has been investigated for the first time in a woody plant species, $V$. vinifera. Our bioinformatic approach led to the identification of 79 sequences that were characterized in terms of gene structure and resulted in the annotation of $46 D E F L$. The grapevine $D E F L$ gene family appears to be smaller compared with the ones previously identi-

Table 1. Inhibition of the germination of Botrytis cinerea conidia by grape defensin-like sequences (DEFL) reported as $\mathrm{IC}_{50}{ }^{\mathrm{a}}$

\begin{tabular}{lc}
\hline DEFL & IC $_{\mathbf{5 0}}(\boldsymbol{\mu g} / \mathbf{m l})$ \\
\hline 13 & $5.3 \pm 0.1$ \\
22 & $14.0 \pm 2.3$ \\
31 & $30.4 \pm 1.4$ \\
59 & $49.7 \pm 3.3$ \\
\hline
\end{tabular}

a Shown are the DEFL identifier and the corresponding half maximal inhibitory concentration $\left(\mathrm{IC}_{50}\right) \pm$ standard deviations $(n=3)$. 
fied with a similar approach in grasses and legumes (Graham et al. 2004; Silverstein et al. 2005, 2007). Only 54\% of the grapevine $D E F L$ genes matched to an existing gene prediction when compared with the two available grapevine genomes (Jaillon et al. 2007; Velasco et al. 2007), confirming that current annotation approaches stumble when predicting genes of small size (Silverstein et al. 2005, 2007), and that the annotation of draft genomes like those for grapevine is still far from complete.

\section{$D E F L$ have undergone large independent expansions in grapevine and other plant species.}

The divergence of $D E F L$ in grapevine is significant, making attempts to align the entire family of 79 members intractable. Indeed, as exemplified by the phylogenetic analysis in Figure 2 , it is clear that ancestral $D E F L$ that existed in the common ancestor of grapevine, Arabidopsis, and Medicago spp. underwent significant independent expansions in each of these three species. This is entirely consistent with the observation of large taxa-specific subgroups among various plant orders for DEFL (Silverstein et al. 2005) and CRP in general (Silverstein et al. 2007). For grapevine, a particularly large expansion has occurred in two DEFL lineages. This is revealed in Figure 2A (26 members versus 7 in Arabidopsis and 0 in Medicago) and Figure 2B ( 8 members versus 0 in the other two species). Further, the largest cluster is clearly undergoing a rapid expansion, accumulating a large number of pseudogenes $(n=8)$, similar to the pattern observed with the recent expansion of $\alpha$ defensins in mammalian lineages (Patil et al. 2004).

\section{DEFL gene structure and genomic organization.}

Defensin genes are characterized by a classical gene structure of two exons and one intron, although exceptions were previously reported (Houlne et al. 1998). The majority of DEFL genes examined here display such typical structure, with two exons generally of conserved length and one intron of more variable size. Some $D E F L$ classified as fragments display a methionine residue early in the DEFL motif, and may also fall in the category of small genes, with just one exon or mispredicted 5' end (Supplementary Fig. S6). Additional experiments will be required to determine their gene structure.

Plant resistance genes often evolve from several duplication mechanisms such as tandem duplications (Ashfield et al. 2003; Graham et al. 2002; Meyers et al. 2005) and occur in clusters. $D E F L$ genes appeared both as single genes and as cluster in the genomes of $A$. thaliana and rice (Silverstein et al. 2007), and a certain degree of clustering and tandem duplications was likewise found in grapevine. The most relevant case is that of group 2, where $18 D E F L$ genes and pseudogenes are highly duplicated in less than $200 \mathrm{~kb}$ on chromosome 10 . This region is densely rich in transposable elements, which may explain the high duplication rate of DEFL. A synteny analysis of Arachis spp. with Lotus and Medicago spp. revealed that a high density of retrotransposons coincides with a rapidly evolving portion of the genome and often contains resistance genes (Bertioli et al. 2009). Tandem duplications of group 2 DEFL may result in increased transcript and protein accumulation or functional diversification. Indeed, the elevated expression of subgroup 2-1 may be due to the high copy number. Frame shifts at the intron splicing sites and stop codons in the first exon appear in eight duplicated nonfunctional genes of this subgroup. In many cases, however, these genes display a point mutation which may provide an alternative translation start for a short yet functional peptide that still retains the characteristic cysteine pattern typical of DEFL but missing the signal peptide. Increased variability of this group of proteins may increase their antibiotic spectrum.
$V \boldsymbol{v}-A M P 1$ expression pattern may be cultivar specific.

$V v-A M P 1$ was previously reported to be a berry-specific defensin gene (de Beer and Vivier 2008) in 'Pinotage'. In contrast, our findings show that $V v-A M P l$ is expressed especially in the berry flesh (mesocarp) but also in leaves, roots, and flowers of 'Pinot Noir'. This discrepancy might be explained by a varietal different expression, as corroborated by EST analysis. EST corresponding to $V v-A M P 1$ were found exclusively expressed in ripe berries of 'Cabernet Sauvignon' but in prevéraison, véraison, and ripening stages of 'Chardonnay' berries (Goes da Silva et al. 2005).

We could also discriminate between the two allelic forms (DEFL 22 and 23), and detect that the DEFL 22 transcript predominates over DEFL 23 in seeds. Further, DEFL 23 is slightly induced in grape infected with B. cinerea, whereas DEFL 22 is not. DEFL 22 and 23 protein sequences differ by just one amino acid (D or E) in the signal peptide but are identical in the mature protein. At the genomic level, the two alleles share $98.7 \%$ nucleotide identity in their coding sequence and are highly similar also in their $5^{\prime}$ region, suggesting that their differential expression in seeds may be explained by genomic regions located elsewhere.

\section{Role in plant defense of the grapevine DEFL.}

The expression of the identified sequences was evaluated in terms of tissue localization and induction upon pathogens. This analysis revealed that the majority of grapevine DEFL displayed tissue specificity, consistent with an over-representation of CRP in reproductive tissues (Silverstein et al. 2005, 2007) and with the fact that many plant defensins were first isolated from flowers and seeds (Dos Santos et al. 2010; Lay et al. 2003; Leung et al. 2008; Stotz et al. 2009; Tregear et al. 2002).

The response of grapevine to the infection of $P$. viticola has been recently evaluated by several means (Polesani et al. 2008; Polesani et al. 2010; Wu et al. 2010). Consistent with our findings, none of these works reported regulation of DEFL genes upon infection with $P$. viticola. Instead, we observed a significant induction of DEFL 23, 29, 32, and 33 and subgroup 2-1 following the treatment of grape berries or inflorescences with $B$. cinerea. Given the large spectrum antimicrobial activity of defensins (de Beer and Vivier 2008; Games et al. 2008), it was surprising to find that DEFL 29 and 33 were induced in grape berries or flowers challenged by $B$. cinerea but not in leaves infected with $P$. viticola. A possible explanation may rely on the very different mode of infection of these fungi: $B$. cinerea is a necrotroph preferentially found on grape berries and flowers in $V$. vinifera, whereas the oomycete $P$. viticola is an obligate biotroph, thus strictly dependent on living host cells for its survival. Tissue colonization by $B$. cinerea involves penetration of the cuticle and the cell wall, and is mainly initiated by wounds. $P$. viticola preferentially penetrates leaves through the stomata, and tissue colonization involves intercellular mycelial growth and the differentiation of haustoria, which penetrate parenchyma cells by invaginating but not breaking the plasma membrane.

Based on these results, we selected three induced $D E F L$ (DEFL 13, 22, and 59), plus an additional DEFL which displayed tissue specificity (DEFL 31), to be tested for their ability to inhibit the growth of Botrytis spp. B. cinerea is a widehost-range fungal pathogen against which several defensins from various plant species were reported to display activity with different efficiencies and $\mathrm{IC}_{50}$ values (Osborn et al. 1995). In our activity tests, all recombinant DEFL were capable of inhibition of $B$. cinerea mycelial growth, and the most effective against $B$. cinerea (DEFL 13) corresponded to the most induced transcript (subgroup 2-1). The weaker activity of DEFL 31 and 59 may be explained either by their being more specifically active against other pathogens or by defense not being 
their primary function. In the case of DEFL 22, we obtained inhibition in the same concentration range reported by de Beer and Vivier (2008). In light of these results, we propose to name the three novel defensins 13, 31, and 59 as Vv-AMP2, VvAMP3, and Vv-AMP4, respectively.

Assuming that the main scope of the plant is to achieve reproduction, protection of the berry would be especially needed in stages preceding véraison, when the seed has not yet developed a protective lignified coat. This is also supported by our discovery of the novel defensin Vv-AMP3 (DEFL 31), expressed specifically in seeds at the pre-véraison stage, together with pretty much all other seed-specific DEFL genes examined, in which expression seems to switch off at véraison (DEFL 30 being the only exception). As already noted via Northern blot analysis by de Beer and Vivier (2008), Vv-AMPl expression instead increased along véraison and ripening and not in the presence of $B$. cinerea. In our work, we detected a slight upregulation of DEFL 23 in berries upon infection but this apparent inconsistency may be due to the superior sensitivity of qPCR, which can also distinguish between two allelic variants of the same gene. We also observed that the $V v-A M P l$ transcript decreases rapidly in detached inflorescences and that the process is accelerated by Botrytis infection. Taken together, these data may suggest that Vv-AMP1 may fulfill functions other than defense, and which may be distinct in berry and inflorescence.

The protection of inflorescences against Botrytis spp. is likely fulfilled by Vv-AMP4 (DEFL 59) and the more active Vv-AMP2 (DEFL 13), although their concomitant expression and different extent of induction of transcription may suggest a different target or even a different function for Vv-AMP4 in inflorescences. Indeed, several $D E F L$ genes were isolated from reproductive tissues with functions unrelated to defense such as a pollen coat DEFL with a role in self-incompatibility in Brassica spp. (Doughty et al. 1998; Takayama et al. 2001), and DEFL specifically localized in synergid cells were recently shown to function in pollen burst in Zea mays (Amien et al. 2010) and pollen tube attraction (Okuda et al. 2009) in Torenia fournieri flowers. It is plausible to think that similar functions are also present in grapevine, and may be exerted by $D E F L$ with low expression, limited to a particular cell type.

The molecular mechanisms underneath the inhibitory activity of defensins are various and still debated; however, it is known that the interaction of these peptides with the target membrane is a crucial step for their antimicrobial action (Aerts et al. 2008). The loss of anti-Botrytis spp. activity that follows the reduction and alkylation of DEFL 13, 22, 31, and 59 indicates that, for these peptides, the disulfide bridges necessary for folded tertiary structures are crucial for antimicrobial activity. Disruption of disulfide bonds of Nad1, a defensin from Nicotiana alata, also resulted in the loss of antifungal activity (van der Weerden et al. 2008). This is in contrast to the radish Rs- $\mathrm{AFP}_{2}$, which retained its antifungal potency even as a shortened 17-amino-acid-long peptide in which cysteine residues were replaced (Schaaper et al. 2001).

None of the tested DEFL display a morphogenetic action on the treated fungal mycelium. Indeed, in addition to the growth inhibitory activity, a number of defensin peptides such as the Rs- $\mathrm{AFP}_{2}$ and the Heuchera sanguinea Hs-AFP1 are capable of hyphae swelling and hyperbranching on some fungal pathogens (Osborn et al. 1995). Nonetheless, the molecular mechanisms regulating this morphogenic action is still unknown.

\section{MATERIALS AND METHODS}

\section{Genomic search of putative $D E F L$ genes.}

Two separate methods were used to search for putative DEFL genes in the 'Pinot Noir' ENTAV115 genome sequence.
In one case, all genomic sequences were scanned using "fgenesh" to predict genes and proteins. This generated a total of 100,408 genes. All predicted genes were scanned with "hmmpfam" against a concatenated file containing the full collection of all 500+ CRP HMM (Silverstein et al. 2007). The results of this search were filtered to accept those with an $E$ value $<0.01$, resulting in 3,701 hits. Finally, this restricted set of genes was further filtered to include only those with a clear signal peptide by scanning with the SignalP program (probability $\geq 0.9$ ). This resulted in 397 gene models. In order to find $D E F L$ genes not predicted with this procedure, we employed a second method. The initial 59,140 genomic sequences (contigs) were broken up into 2,000-bp fragments that overlapped by $1,000 \mathrm{bp}$. These 2,000-bp fragments were translated in all six frames, resulting in 3,284,013 fragmented peptides. These peptide fragments were scanned with hmmpfam against the same 500+ CRP HMM as above, again accepting those with $E$ value $<0.01$. SignalP was not applied to the set because the identified fragmentary sequences were not expected to represent full open reading frames. In all, 2,431 fragmentary peptides were identified. All DEFL hits (CRP0000 to CRP1540) from methods 1 and 2 with $E$ value $<1 \mathrm{e}-04$ were automatically collected and assigned to their CRP subgroup that had the most significant $E$ value. DEFL hits with $E$ values between 0.01 and $1 \mathrm{e}-04$ were visually inspected and retained if they had a clear six- or eight-cysteine motif characteristic of the family. In total, $64 D E F L$ were identified. Additional sequences were found by blasting the $64 D E F L$ against the 'Pinot Noir' genome, to a total of 79 sequences and two additional gene models. Information about gene structure was obtained with a combination of intron splicing site predictions and BLAST searches against available plant EST, and were experimentally determined by $5^{\prime}$-RACE experiments and amplification from cDNA with intron-spanning primers.

\section{Phylogenetic analysis.}

The nucleotide sequences for all grapevine DEFL were clustered and aligned with ClustalW (Thompson et al. 2002). The resulting dendrogram was used to identify the four clusters that were present having at least four members. The nucleotide sequences of grapevine $D E F L$ within these four groups were clustered one group at a time with all 281 non-pseudogene Arabidopsis DEFL coding sequences from TAIR 10. Any Arabidopsis homologs that grouped with the set of grapevine $D E F L$ in the dendrogram were added to the group. The same procedure was subsequently applied using the 106 "non-nodule DEFL" (i.e., belonging to subgroups CRP0000 to CRP1110) (Silverstein et al. 2007) from Medicago IMGAG $3.5 \mathrm{v} 4$ (Young et al. 2011). All grapevine, Arabidopsis, and Medicago nucleotide sequences belonging to one of the four groups were realigned using PRANK (Löytynoja and Goldman 2010). The resulting alignments for these four groups (Supplementary Fig. S7) were manually edited in JalView (Waterhouse et al. 2009) to remove all columns with gaps and whole subranges of sequence columns that consisted of fewer than two residues surrounded by gaps. This resulted in alignments consisting of $31,8,17$, and 9 sequences, with 136, 161, 73, and 138 characters for the respective groups. Each of the four trimmed alignments were used as input to both the neighborjoining algorithm (Saitou and Nei 1987) and the MrBayes v. 3.2 phylogenetic inference package (Ronquist and Huelsenbeck 2003). For the latter, the default general time-reversible model of evolution with invariant sites and gamma-distributed rates was used. In all, 2 million Monte Carlo generations were used for the first group but only 1 million generations were needed for convergence of the parameters for the remaining three groups. 


\section{Plant tissues.}

All plant material used in this study came from plants of $V$. vinifera $\mathrm{cv}$. Pinot Noir, clone ENTAV115, either grown in pots under greenhouse conditions or harvested from a vineyard located in San Michele all'Adige (Italy). Véraison was determined by profiling the malic and tartaric acid and sugar content in clusters randomly sampled in the vineyard. Inflorescences were harvested at anthesis unless differently specified. All harvested material was immediately frozen in liquid nitrogen and stored at $-80^{\circ} \mathrm{C}$ until use.

\section{Pathogen growth and plants inoculation.}

The fungus $P$. viticola was isolated from an untreated 'Pinot Noir' vineyard in the Trentino region (Italy) and maintained on 'Pinot Noir' plants grown in greenhouse conditions. Inoculation of pot-grown young 'Pinot Noir' plants and assessment of the disease symptoms was performed essentially as described by Perazzolli and coauthors (2011). The abaxial side of leaves was sprayed with a suspension of $P$. viticola fresh sporangia adjusted to $10^{5} / \mathrm{ml}$ with cold water. Inoculated plants were incubated overnight in the dark at $25^{\circ} \mathrm{C}$ with 99 to $100 \%$ relative humidity $(\mathrm{RH})$, then maintained under the controlled greenhouse conditions for plant growth. Six days after inoculation, plants were incubated in the darkness at $25^{\circ} \mathrm{C}$ with 99 to $100 \%$ RH to allow downy mildew sporulation and assess disease severity (Perazzolli et al. 2011). Leaves were harvested $48 \mathrm{~h}$ postinoculation from three plants showing symptoms of infection. Control leaves were obtained from noninfected plants grown in parallel and mock inoculated.

The fungus $B$. cinerea was isolated from an untreated vineyard of 'Cabernet Sauvignon' in the Trentino region (Italy), and cultivated on potato dextrose agar (Sigma, St. Louis) or skim milk medium (Sigma) at $25^{\circ} \mathrm{C}$ for 7 to 10 days for development of conidiophores. Conidia were harvested by wetting the surface of the plate with a few milliliters of a $0.9 \%$ (wt/vol) $\mathrm{NaCl}$ solution. Conidia were then separated from the broken mycelium by centrifugation at 3,000 $\times g$ for $3 \mathrm{~min}$, suspended in sterile $0.9 \%(\mathrm{wt} / \mathrm{vol}) \mathrm{NaCl}$ and $0.1 \%(\mathrm{wt} / \mathrm{vol})$ glucose, and adjusted to approximately $10^{6} / \mathrm{ml}$ spores. Inflorescences were harvested from pot-grown plants maintained in greenhouse conditions a few days past anthesis, when almost all caps had fallen and sepals started to detach; they were then sprayed with a sterile solution of $0.9 \%$ (wt/vol) $\mathrm{NaCl}$ and $0.1 \%$ (wt/vol) glucose (mock) or the B. cinerea conidia suspension and maintained in a plastic box to retain humidity. At 2 and 4 days after treatment, inflorescences were frozen in liquid nitrogen. For the infection experiment on grape berries, clusters were harvested a few days after véraison from the vineyard and blandly washed with $1 \%$ (vol/vol) commercial bleach. Botrytis conidia were then applied on the grape berries by spraying the conidia suspension in a sterile solution of $0.9 \%(\mathrm{wt} / \mathrm{vol}) \mathrm{NaCl}$ and $0.15 \%$ glucose (wt/vol), or mock. Grape berries were punctured with a sterile needle to favor infection and kept in sealed boxes with high humidity and at room temperature. Grape samples were taken at 3 and 5 days postinfection, were frozen in liquid nitrogen, and were kept at $-80^{\circ} \mathrm{C}$ until use. RNA was then extracted from grape berries (exocarp and mesocarp) separated from seeds of botrytized and control clusters, and used for gene expression analysis.

The success of infection, both for inflorescences and grape berries, was evaluated by macroscopic observation of the developing mycelium already at 2 days after inoculation, visualization of germinating spores under the microscope, and amplification of cDNA prepared from infected and control tissues using primers specific for a $B$. cinerea laccase gene (Ferrarini et al. 2007) (Supplementary Table S3).
RNA extraction, cDNA synthesis, and 5'-RACE.

RNA was extracted from 11 different organs/tissues of 'Pinot Noir' plants in three independent biological replicates (taken from three different plants): leaf (L), root (R), inflorescence (I), and grape berries at three maturation stages. Grape samples were separated into skin $\left(\mathrm{Sk}_{1}, \mathrm{Sk}_{2}\right.$, and $\left.\mathrm{Sk}_{3}\right)$, flesh $\left(\mathrm{F}_{1}, \mathrm{~F}_{2}\right.$, and $\left.\mathrm{F}_{3}\right)$ and seeds $\left(\mathrm{Se}_{1}\right.$ and $\left.\mathrm{Se}_{2}\right)$, where digits correspond to the three maturation stages: $1=2$ weeks prior to véraison, 2 = at véraison, and $3=2$ weeks postvéraison. Due to poor-quality RNA obtained from seeds in mature grape berries (due to lignification and high oil content), this tissue was excluded from the qPCR analysis. In addition, RNA was extracted from inflorescences, grape berries (exocarp and mesocarp) from clusters inoculated by $B$. cinerea or mock solution, and leaves sprayed with $P$. viticola or mock. RNA extraction was performed with Spectrum Plant Total RNA Kit (Sigma) according to the manufacturer's instructions. RNA was quantified with a ND-8000 nanodrop spectrophotometer and checked for integrity with a 2001-bioanalyzer (Agilent, Santa Clara, CA, U.S.A.). For expression analysis, cDNAs were synthesized with Superscript RT III (Life technologies Ltd., Paisley, U.K.) from $1.5 \mu \mathrm{g}$ of DNAse-treated RNA (DNAse I; Life technologies Ltd.). cDNA was diluted 10 times prior to PCR or qPCR.

\section{Experimental determination of gene structure.}

Amplification of $5^{\prime}$ ends was performed with the $5^{\prime}$-RACE system (Invitrogen) using an oligo- $\mathrm{dT}_{20}$ or a gene-specific primer for first-strand cDNA synthesis. Amplified RACE products were cloned in pGEMt-easy (Promega Corp., Madison, WI, U.S.A.) and sequenced. Determination of the intron position was obtained by up to 50 cycles of PCR with intron-spanning primers, cloning in pGEMt-easy, and sequencing.

\section{Qualitative expression analysis.}

cDNA pools from $\mathrm{L}, \mathrm{R}$, and I were prepared by mixing cDNA obtained from three independent biological replicates of each tissue. cDNA pools of grape Sk, F, and Se were prepared by mixing cDNA obtained from tissues at the different ripening stages as follows: Sk cDNA was prepared by mixing three biological replicates of cDNA obtained from $\mathrm{Sk}_{1}, \mathrm{Sk}_{2}$, and $\mathrm{Sk}_{3} ; \mathrm{F}$ cDNA was prepared by mixing three biological replicates of cDNA obtained from $\mathrm{F}_{1}, \mathrm{~F}_{2}$, and $\mathrm{F}_{3}$; and Se cDNA was prepared by mixing three biological replicates of cDNA of $\mathrm{Se}_{1}$ and $\mathrm{Se}_{2}$. Digits correspond to three grape ripening stages: $1=2$ weeks prior to véraison, $2=$ at véraison, and $3=2$ weeks postvéraison. Then, $1 \mu \mathrm{l}$ of each cDNA pool was used for amplification with $D E F L$-specific primers, using 40 cycles of PCR in a $30-\mu l$ reaction. The cDNA pools were tested for contamination from genomic DNA by amplification of DEFL 8 with intron-spanning primers (8-FORWARD-1 and 8-REVERSE-1), and no amplification was obtained with up to 50 cycles.

\section{Quantitative PCR.}

Specificity of the primers for qPCR was tested by sequencing the PCR product.

Real-time PCR was performed with Platinum Syber Green qPCR SuperMix-UDG (Life technologies Ltd.) in an ABI PRISM 7000 thermocycler (Applied Biosystems, Foster City, CA, U.S.A.). Plates were set up according to the sample maximization strategy proposed in (Hellemans et al. 2007), and each reaction was run in triplicate. Reactions were set with two initial steps at $55^{\circ} \mathrm{C}$ for $10 \mathrm{~min}$ and $95^{\circ} \mathrm{C}$ for $2 \mathrm{~min}$, followed by 40 cycles of $95^{\circ} \mathrm{C}$ for $15 \mathrm{~s}$ plus $60^{\circ} \mathrm{C}$ for $1 \mathrm{~min}$. The specificity of the amplification was evaluated with a dissociation curve: DEFL 22 and 23 were distinguished in qPCR on 
the basis of their different melting temperatures, which were $79.775^{\circ} \mathrm{C}\left( \pm 0.15^{\circ} \mathrm{C}\right)$ for $D E F L 22$ and 79 and $417^{\circ} \mathrm{C}\left( \pm 0.17^{\circ} \mathrm{C}\right)$ for DEFL 23. Mean amplification efficiencies (Eff) for each primers pair were calculated with the LinReg software (Ruijter et al. 2009) and used to calculate relative quantities (RQ) accord-

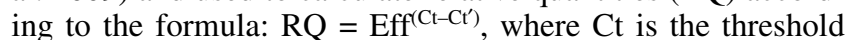
cycle and $\mathrm{Ct}^{\prime}$ is the average $\mathrm{Ct}$ among all samples analyzed in one experiment. Six housekeeping genes (EFl $\alpha, G A P D H, A C$ TIN, UBIQUITIN, SAND, and $\alpha-T U B U L I N)$ were tested for their stability in each experiment using the GeNorm software (Vandesompele et al. 2002). Normalized relative quantities (NRQ) were then calculated by dividing RQ by a normalization factor, based on the expression of the two or three more stable reference genes (Reid et al. 2006). In the qPCR analysis of genes induced by pathogens, statistical significance was evaluated with the Student's $t$ test calculated on the $\log _{2}$ (NRQ), according to Rieu and Powers (2009)

\section{Calculation of molecular properties.}

Splicing sites were predicted using GeneSplicer (Pertea et al. 2001). Signal peptides were predicted using the SignalP 3.0 server (Bendtsen et al. 2004). Theoretical pI were calculated using ExPASy's pI/MW tool (Gasteiger et al. 2005). BLAT search was performed using the BLAT search tool at Genoscope on the $12 \mathrm{x}$ genome database

\section{Production of recombinant grape defensins.}

Primers containing specific extensions were used to amplify the mature form of DEFL 13, 22, 31, and 59 from cDNAs. The amplification product of DEFL 22 was cloned into a pET32 vector (Novagen) for expression of a TRX fusion protein with a His tag. Once sequenced, recombinant plasmids were used to transform E. coli Rosetta Gami strain (Merk KgaA, Darmstadt, Germany). Bacterial cell cultures grown to an optical density at $600 \mathrm{~nm}\left(\mathrm{OD}_{600}\right)$ of 0.5 were induced with $0.4 \mathrm{mM}$ isopropyl 1-thio-b-D-galactopyranoside (IPTG) overnight at $20^{\circ} \mathrm{C}$. Cell pellets were suspended in $50 \mathrm{mM}$ phosphate $(\mathrm{pH} 8), 0.3 \mathrm{M}$ $\mathrm{NaCl}, 20 \mathrm{mM}$ imidazole, and 10\% (vol/vol) glycerol and disrupted by French Press. Cleared cell lysates were applied to a 5-ml Ni2+-IMAC column (GE Healthcare, Piscataway, NJ, U.S.A.) and proteins eluted with $0.5 \mathrm{M}$ imidazole. Proteincontaining fractions were identified by sodium dodecyl sulfate polyacrylamide gel electrophoresis (SDS-PAGE), pooled, and then dyalized against $20 \mathrm{mM}$ Tris- $\mathrm{HCl}(\mathrm{pH} \mathrm{8)}, 50 \mathrm{mM} \mathrm{NaCl}, 2$ $\mathrm{mM} \mathrm{CaCl}$, and $1 \%$ (vol/vol) Tween-20. The His-TRX tag was removed by overnight digestion at $20^{\circ} \mathrm{C}$ with $0.001 \%$ (wt/wt) enterokinase and the recombinant protein was further purified using cation exchange chromatography (MONO-S column; GE Healthcare) and its purity was evaluated by SDS-PAGE. Amplification products of DEFL 13, 31, and 59 were cloned into the pOPIN $\mathrm{M}$ vector for expression with an MBP tag following the manufacturer's protocol (Berrow et al. 2007). Recombinant plasmids were sequenced and transformed into BL21 (DE3) cells. Bacterial cultures were grown at $37^{\circ} \mathrm{C}$ in selective media (carbenicillin at $100 \mu \mathrm{g} / \mathrm{ml}$ ) to an $\mathrm{OD}_{600}$ of 0.4 to 0.6 prior to induction with $1 \mathrm{mM}$ IPTG for $3 \mathrm{~h}$. Pelleted cell cultures were suspended in $50 \mathrm{mM}$ Tris- $\mathrm{HCl}(\mathrm{pH} 8), 500 \mathrm{mM}$ $\mathrm{NaCl}, 20 \mathrm{mM}$ imidazole, $50 \mathrm{mM}$ glycine, and $20 \%$ (vol/vol) glycerol and lysed by a constant cell disruption systems (Constant Systems Ltd., Northants, U.K.). The cleared lysates were applied to 5-ml Ni2+-IMAC columns and proteins eluted with $0.5 \mathrm{M}$ imidazole. Protein-containing fractions were identified by SDS-PAGE, pooled, and concentrated, then injected into a Hi-Load 16/60 Superdex 75 column (GE Healthcare) preequilibrated with $20 \mathrm{mM}$ HEPES (pH 7.5) and $150 \mathrm{mM} \mathrm{NaCl}$. The MBP tag was removed by digestion with $\mathrm{C} 3$ protease (12 $\mu \mathrm{g} / \mathrm{mg}$ of fusion protein) overnight at $4^{\circ} \mathrm{C}$, and further purified using an MBP trap and a HIS trap column, respectively $(5 \mathrm{ml})$ (GE Healthcare). The flow-through was then concentrated and injected into a Hi-Load 16/60 Superdex 75 column preequilibrated with $20 \mathrm{mM}$ HEPES ( $\mathrm{pH} 7.5)$ and $150 \mathrm{mM} \mathrm{NaCl}$. The protein-containing fractions were pooled and concentrated and their purity was confirmed by SDS-PAGE. Proteins were quantified by their absorbance at $280 \mathrm{~nm}$ using the corresponding calculated $\varepsilon$. Following removal of the fusion partner, proteins were purified to a final yield of approximately $0.2 \mathrm{mg}$ per liter of bacterial culture. The method of Ellman was used to confirm a lack of free thiols in the purified proteins (Ellman 1958).

\section{In vitro antimicrobial activity against $B$. cinerea .}

The in vitro antimicrobial activity against $B$. cinerea was assayed by both visualization of spore germination and mycelium growth at the microscope and spectrophotometric determination of the $\mathrm{IC}_{50}$. The in vitro assays were performed in 96well microtiter plates containing $100 \mu \mathrm{l}$ of half potato dextrose broth with $B$. cinerea at $5 \times 10^{4}$ spores $/ \mathrm{ml}$ and the purified DEFL at a concentration of 0 to $50 \mu \mathrm{g} / \mathrm{ml}$. Plates were left at $20^{\circ} \mathrm{C}$ for 3 days. After $16 \mathrm{~h}$, conidia germination was checked with an inverted microscope. Quantitative antifungal activity of the grape DEFL was measured by microspectrophometry (Broekaert et al. 1990). Buffer containing Botrytis conidia and buffer with the addition of the reduced and alkylated form of each recombinant DEFL were used as controls. Samples were reduced by addition of $2 \mathrm{mM}$ Tris(2-carboxyethyl) phosphine hydrochloride and incubation for $5 \mathrm{~min}$ at $95^{\circ} \mathrm{C}$, and alkylated by the addition of $15 \mathrm{mM}$ iodoacetic acid to the cooled reaction mixtures and incubation for $30 \mathrm{~min}$ in the dark. The samples were dialyzed overnight at $4^{\circ} \mathrm{C}$ against $20 \mathrm{mM}$ HEPES $(\mathrm{pH} 7.5)$ and $150 \mathrm{mM} \mathrm{NaCl}$ and quantified. Microspectrophometry readings were taken after 24,48 , and $60 \mathrm{~h}$ at 540 $\mathrm{nm}$, and corrected for their time zero readings. DEFL activities were scored after $60 \mathrm{~h}$ and expressed in terms of percent growth inhibition, which is defined as $100 \times\left(\mathrm{ABS}_{540}-\right.$ $\left.\mathrm{ABS}_{540}{ }^{\mathrm{control}}\right) /\left(\mathrm{ABS}_{540}{ }^{\mathrm{control}}\right)$, where $\mathrm{ABS}_{540}$ is the corrected absorbance measured at $540 \mathrm{~nm}$. Each activity assay was repeated twice with independent $B$. cinerea cultures.

\section{ACKNOWLEDGMENTS}

We thank M. Perazzolli and C. Sicher for help with the infection experiments with $P$. viticola and B. cinerea, A. Cestaro and M. Moretto at the Edmund Mach Foundation for help with transposons annotation, R. Hughes at the JIC-Norwich for help with recombinant protein expression, and A. Geerolf at EMBL-Heidelberg for the provision of the 3C-protease encoding expression plasmid. This work was financially supported by the Fondazione Cassa di Risparmio di Trento e Rovereto (Project "Difensine", Bando 2007/2008 per progetti di ricerca scientifica applicata nell'ambito delle biotecnologie).

\section{LITERATURE CITED}

Aerts, A. M., Francois, I. E., Cammue, B. P., and Thevissen, K. 2008. The mode of antifungal action of plant, insect and human defensins. Cell. Mol. Life Sci. 65:2069-2079

Amien, S., Kliwer, I., Márton, M. L., Debener, T., Geiger, D., Becker, D., and Dresselhaus, T. 2010. Defensin-like ZmES4 mediates pollen tube burst in maize via opening of the potassium channel KZM1. PLoS Biol. 8:e1000388.

Ashfield, T., Bocian, A., Held, D., Henk, A. D., Marek, L. F., Danesh, D., Penuela, S., Meksem, K., Lightfoot, D. A., Young, N. D., Shoemaker, R. C., and Innes, R. W. 2003. Genetic and physical localization of the soybean Rpg1-b disease resistance gene reveals a complex locus containing several tightly linked families of NBS-LRR genes. Mol. PlantMicrobe Interact. 16:817-826.

Bendtsen, J. D., Nielsen, H., von Heijne, G., and Brunak, S. 2004. Improved prediction of signal peptides: SignalP 3.0. J. Mol. Biol. 340:783-795.

Berrow, N. S., Alderton, D., Sainsbury, S., Nettleship, J., Assenberg, R., Rahman, N., Stuart, D. I., and Owens, R. J. 2007. A versatile ligation- 
independent cloning method suitable for high-throughput expression screening applications. Nucleic Acids Res. 35:e45.

Bertioli, D., Moretzsohn, M., Madsen, L., Sandal, N., Leal-Bertioli, S., Guimaraes, P., Hougaard, B., Fredslund, J., Schauser, L., Nielsen, A., Sato, S., Tabata, S., Cannon, S., and Stougaard, J. 2009. An analysis of synteny of Arachis with Lotus and Medicago sheds new light on the structure, stability and evolution of legume genomes. BMC Genomics $10: 45$.

Broekaert, W. F., Terras, F. R. G., Cammue, B. P. A., and Vanderleyden, J. 1990. An automated quantitative assay for fungal growth inhibition. FEMS (Fed. Eur. Microbiol. Soc.) Microbiol. Lett. 69:55-60.

Carvalho, A. O., and Gomes, V. M. 2009. Plant defensins-prospects for the biological functions and biotechnological properties. Peptides 30:1007-1020.

Cornet, B., Bonmatin, J.-M., Hetru, C., Hoffmann, J. A., Ptak, M., and Vovelle, F. 1995. Refined three-dimensional solution structure of insect defensin A. Structure 3:435-448.

de Beer, A., and Vivier, M. A. 2008. Vv-AMP1, a ripening induced peptide from Vitis vinifera shows strong antifungal activity. BMC Plant Biol. $8: 75$.

Dos Santos, I. S., Carvalho, A. O., de Souza-Filho, G. A., do Nascimento, V. V., Machado, O. L., and Gomes, V. M. 2010. Purification of a defensin isolated from Vigna unguiculata seeds, its functional expression in Escherichia coli, and assessment of its insect alpha-amylase inhibitory activity. Protein Expr. Purif. 71:8-15.

Doughty, J., Dixon, S., Hiscock, S. J., Willis, A. C., Parkin, I. A., and Dickinson, H. G. 1998. PCP-A1, a defensin-like Brassica pollen coat protein that binds the S locus glycoprotein, is the product of gametophytic gene expression. Plant Cell 10:1333-1347.

Dresselhaus, T., and Márton, M. L. 2009. Micropylar pollen tube guidance and burst: Adapted from defense mechanisms? Curr. Opin. Plant Biol. 12:773-780.

Ellman, G. L. 1958. A colorimetric method for determining low concentrations of mercaptans. Arch. Biochem. Biophys. 74:443-450.

Ferrarini, R., Nicolis, E., Spinelli, P., Torriani, S., and Tornielli, G. B. 2007. Research on the conditions of noble rot infection and its effects on berry composition during post-harvest of grapes for the production of Recioto of Soave. In: XXX World Congress of Vine and Wine, Budapest.

Feschotte, C., Jiang, N., and Wessler, S. R. 2002. Plant transposable elements: Where genetics meets genomics. Nat. Rev. Genet. 3:329-341.

Games, P. D., Dos Santos, I. S., Mello, E. O., Diz, M. S., Carvalho, A. O., de Souza-Filho, G. A., Da Cunha, M., Vasconcelos, I. M., Ferreira Bdos, S., and Gomes, V. M. 2008. Isolation, characterization and cloning of a cDNA encoding a new antifungal defensin from Phaseolus vulgaris L. seeds. Peptides 29:2090-2100.

Gao, A. G., Hakimi, S. M., Mittanck, C. A., Wu, Y., Woerner, B. M., Stark, D. M., Shah, D. M., Liang, J., and Rommens, C. M. 2000. Fungal pathogen protection in potato by expression of a plant defensin peptide. Nat. Biotechnol. 18:1307-1310.

Gassmann, W., Hinsch, M. E., and Staskawicz, B. J. 1999. The Arabidopsis RPS4 bacterial-resistance gene is a member of the TIR-NBS-LRR family of disease-resistance genes. Plant J. 20:265-277.

Gasteiger, E., Hoogland, C., Gattiker, A., Duvaud, S., Wilkins, M. R., Appel, R. D., and Bairoch, A. 2005. Protein identification and analysis tools on the ExPASy server. Pages 571-607 in: The Proteomics Protocols Handbook. J. M. Walker, ed. Humana Press, Totowa, NJ, U.S.A

Goes da Silva, F., Iandolino, A., Al-Kayal, F., Bohlmann, M. C., Cushman, M. A., Lim, H., Ergul, A., Figueroa, R., Kabuloglu, E. K., Osborne, C., Rowe, J., Tattersall, E., Leslie, A., Xu, J., Baek, J., Cramer, G. R., Cushman, J. C., and Cook, D. R. 2005. Characterizing the grape transcriptome. analysis of expressed sequence tags from multiple Vitis species and development of a compendium of gene expression during berry development. Plant Physiol. 139:574-597.

Graham, M. A., Marek, L. F., and Shoemaker, R. C. 2002. Organization, expression and evolution of a disease resistance gene cluster in soybean. Genetics 162:1961-1977.

Graham, M. A., Silverstein, K. A., Cannon, S. B., and VandenBosch, K. A. 2004. Computational identification and characterization of novel genes from legumes. Plant Physiol. 135:1179-1197.

Hellemans, J., Mortier, G., De Paepe, A., Speleman, F., and Vandesompele, J. 2007. qBase relative quantification framework and software for management and automated analysis of real-time quantitative PCR data. Genome Biol. 8:R19.

Houlne, G., Meyer, B., and Schantz, R. 1998. Alteration of the expression of a plant defensin gene by exon shuffling in bell pepper (Capsicum annuит L.). Mol. Gen. Genet. 259:504-510.

Jaillon, O., Aury, J. M., Noel, B., Policriti, A., Clepet, C., Casagrande, A., Choisne, N., Aubourg, S., Vitulo, N., Jubin, C., Vezzi, A., Legeai, F., Hugueney, P., Dasilva, C., Horner, D., Mica, E., Jublot, D., Poulain, J.,
Bruyère, C., Billault, A., Segurens, B., Gouyvenoux, M., Ugarte, E., Cattonaro, F., Anthouard, V., Vico, V., Del Fabbro, C., Alaux, M., Di Gaspero, G., Dumas, V., Felice, N., Paillard, S., Juman, I., Moroldo, M., Scalabrin, S., Canaguier, A., Le Clainche, I., Malacrida, G., Durand, E., Pesole, G., Laucou, V., Chatelet, P., Merdinoglu, D., Delledonne, M., Pezzotti, M., Lecharny, A., Scarpelli, C., Artiguenave, F., Pè, M. E., Valle, G., Morgante, M., Caboche, M., Adam-Blondon, A. F., Weissenbach, J., Quétier, F., and Wincker, P. 2007. The grapevine genome sequence suggests ancestral hexaploidization in major angiosperm phyla. Nature 449:463-467

Janssen, B. J., Schirra, H. J., Lay, F. T., Anderson, M. A., and Craik, D. J. 2003. Structure of Petunia hybrida defensin 1, a novel plant defensin with five disulfide bonds. Biochemistry 42:8214-8222.

Jordan, T., Schornack, S., and Lahaye, T. 2002. Alternative splicing of transcripts encoding Toll-like plant resistance proteins-what's the functional relevance to innate immunity? Trends Plant Sci. 7:392-398

Kovalchuk, N., Li, M., Wittek, F., Reid, N., Singh, R., Shirley, N., Ismagul, A., Eliby, S., Johnson, A., Milligan, A. S., Hrmova, M., Langridge, P., and Lopato, S. 2009. Defensin promoters as potential tools for engineering disease resistance in cereal grains. Plant Biotechnol. J. 8:47-64.

Lawrence, G. J., Finnegan, E. J., Ayliffe, M. A., and Ellis, J. G. 1995. The L6 gene for flax rust resistance is related to the Arabidopsis bacterial resistance gene RPS2 and the tobacco viral resistance gene N. Plant Cell 7:1195-1206.

Lay, F. T., and Anderson, M. A. 2005. Defensins-components of the innate immune system in plants. Curr. Protein Pept. Sci. 6:85-101.

Lay, F. T., Brugliera, F., and Anderson, M. A. 2003. Isolation and properties of floral defensins from ornamental tobacco and petunia. Plant Physiol. 131:1283-1293.

Leung, E. H., Wong, J. H., and Ng, T. B. 2008. Concurrent purification of two defense proteins from French bean seeds: A defensin-like antifungal peptide and a hemagglutinin. J. Pept. Sci. 14:349-353.

Löytynoja, A., and Goldman, N. 2010. webPRANK: A phylogeny-aware multiple sequence aligner with interactive alignment browser. BMC Bioinf. 11:579.

Meyers, B. C., Kaushik, S., and Nandety, R. S. 2005. Evolving disease resistance genes. Curr. Opin. Plant Biol. 8:129-134.

Moran, Y., Weinberger, H., Reitzel, A. M., Sullivan, J. C., Kahn, R., Gordon, D., Finnerty, J. R., and Gurevitz, M. 2008. Intron retention as a posttranscriptional regulatory mechanism of neurotoxin expression at early life stages of the starlet anemone Nematostella vectensis. J. Mol. Biol. 380:437-443.

Okuda, S., Tsutsui, H., Shiina, K., Sprunck, S., Takeuchi, H., Yui, R., Kasahara, R. D., Hamamura, Y., Mizukami, A., Susaki, D., Kawano, N. Sakakibara, T., Namiki, S., Itoh, K., Otsuka, K., Matsuzaki, M., Nozaki, H., Kuroiwa, T., Nakano, A., Kanaoka, M. M., Dresselhaus, T., Sasaki, N., and Higashiyama, T. 2009. Defensin-like polypeptide LUREs are pollen tube attractants secreted from synergid cells. Nature 458:357361.

Osborn, R. W., De Samblanx, G. W., Thevissen, K., Goderis, I., Torrekens, S., Van Leuven, F., Attenborough, S., Rees, S. B., and Broekaert, W. F. 1995. Isolation and characterisation of plant defensins from seeds of Asteraceae, Fabaceae, Hippocastanaceae and Saxifragaceae. FEBS (Fed. Eur. Biochem. Soc.) Lett. 368:257-262.

Patil, A., Hughes, A. L., and Zhang, G. 2004. Rapid evolution and diversification of mammalian alpha-defensins as revealed by comparative analysis of rodent and primate genes. Physiol. Genomics 20:1-11.

Penninckx, I. A., Eggermont, K., Terras, F. R., Thomma, B. P., De Samblanx, G. W., Buchala, A., Metraux, J. P., Manners, J. M., and Broekaert, W. F. 1996. Pathogen-induced systemic activation of a plant defensin gene in Arabidopsis follows a salicylic acid-independent pathway. Plant Cell 8:2309-2323.

Perazzolli, M., Roatti, B., Bozza, E., and Pertot, I. 2011. Trichoderma harzianum T39 induces resistance against downy mildew by priming for defense without costs for grapevine. Biol. Control 58:74-82.

Pertea, M., Lin, X., and Salzberg, S. L. 2001. GeneSplicer: A new computational method for splice site prediction. Nucleic Acids Res. 29:11851190.

Polesani, M., Desario, F., Ferrarini, A., Zamboni, A., Pezzotti, M., Kortekamp, A., and Polverari, A. 2008. cDNA-AFLP analysis of plant and pathogen genes expressed in grapevine infected with Plasmopara viticola. BMC Genomics 9:142.

Polesani, M., Bortesi, L., Ferrarini, A., Zamboni, A., Fasoli, M., Zadra, C., Lovato, A., Pezzotti, M., Delledonne, M., and Polverari, A. 2010. General and species-specific transcriptional responses to downy mildew infection in a susceptible (Vitis vinifera) and a resistant (V. riparia) grapevine species. BMC Genomics 11:117.

Reid, K. E., Olsson, N., Schlosser, J., Peng, F., and Lund, S. T. 2006. An optimized grapevine RNA isolation procedure and statistical determina- 
tion of reference genes for real-time RT-PCR during berry development. BMC Plant Biol. 6:27.

Rieu, I., and Powers, S. J. 2009. Real-time quantitative RT-PCR: Design, calculations, and statistics. Plant Cell 21:1031-1033.

Ronquist, F., and Huelsenbeck, J. P. 2003. MrBayes 3: Bayesian phylogenetic inference under mixed models. Bioinformatics 19:1572-1574.

Ruijter, J. M., Ramakers, C., Hoogaars, W. M., Karlen, Y., Bakker, O., van den Hoff, M. J., and Moorman, A. F. 2009. Amplification efficiency: Linking baseline and bias in the analysis of quantitative PCR data. Nucleic Acids Res. 37:e45.

Saitou, N., and Nei, M. 1987. The neighbor-joining method: A new method for reconstructing phylogenetic trees. Mol. Biol. Evol. 4:406425 .

Schaaper, W. M., Posthuma, G. A., Plasman, H. H., Sijtsma, L., Fant, F., Borremans, F. A., Thevissen, K., Broekaert, W. F., Meloen, R. H., and van Amerongen, A. 2001. Synthetic peptides derived from the beta2beta3 loop of Raphanus sativus antifungal protein 2 that mimic the active site. J. Pept. Res. 57:409-418.

Schornack, S., Ballvora, A., Gürlebeck, D., Peart, J., Ganal, M., Baker, B., Bonas, U., and Lahaye, T. 2004. The tomato resistance protein Bs4 is a predicted non-nuclear TIR-NB-LRR protein that mediates defense responses to severely truncated derivatives of AvrBs4 and overexpressed AvrBs3. Plant J. 37:46-60.

Sels, J., Mathys, J., De Coninck, B. M., Cammue, B. P., and De Bolle, M. F. 2008. Plant pathogenesis-related (PR) proteins: A focus on PR peptides. Plant Physiol. Biochem. 46:941-950.

Silverstein, K. A., Graham, M. A., Paape, T. D., and VandenBosch, K. A. 2005. Genome organization of more than 300 defensin-like genes in Arabidopsis. Plant Physiol. 138:600-610.

Silverstein, K. A., Moskal, W. A., Jr., Wu, H. C., Underwood, B. A. Graham, M. A., Town, C. D., and VandenBosch, K. A. 2007. Small cysteine-rich peptides resembling antimicrobial peptides have been underpredicted in plants. Plant J. 51:262-280.

Stotz, H., Spence, B., and Wang, Y. 2009. A defensin from tomato with dual function in defense and development. Plant Mol. Biol. 71:131-143.

Takayama, S., Shimosato, H., Shiba, H., Funato, M., Che, F.-S., Watanabe, M., Iwano, M., and Isogai, A. 2001. Direct ligand-receptor complex interaction controls Brassica self-incompatibility. Nature 413:534-538.

Terras, F. R., Eggermont, K., Kovaleva, V., Raikhel, N. V., Osborn, R. W., Kester, A., Rees, S. B., Torrekens, S., Van Leuven, F., Vanderleyden, J., Cammue, B., and Broekaert, W. 1995. Small cysteine-rich antifungal proteins from radish: Their role in host defense. Plant Cell 7:573-588.

Thevissen, K., Kristensen, H. H., Thomma, B. P., Cammue, B. P., and Francois, I. E. 2007. Therapeutic potential of antifungal plant and insect defensins. Drug Discov. Today 12:966-971.

Thompson, J. D., Gibson, T. J., and Higgins, D. G. 2002. Multiple sequence alignment using ClustalW and ClustalX. Current Protocols in Bioinformatics. Chapter 2:Unit 23. Wiley, New York.

Tregear, J. W., Morcillo, F., Richaud, F., Berger, A., Singh, R., Cheah, S. C., Hartmann, C., Rival, A., and Duval, Y. 2002. Characterization of a defensin gene expressed in oil palm inflorescences: Induction during tissue culture and possible association with epigenetic somaclonal variation events. J. Exp. Bot. 53:1387-1396.

van der Weerden, N. L., Lay, F. T., and Anderson, M. A. 2008. The plant defensin, NaD1, enters the cytoplasm of Fusarium oxysporum hyphae. J. Biol. Chem. 283:14445-14452.

Vandesompele, J., De Preter, K., Pattyn, F., Poppe, B., Van Roy, N., De Paepe, A., and Speleman, F. 2002. Accurate normalization of real-time quantitative RT-PCR data by geometric averaging of multiple internal control genes. Genome Biol. 3: research0034.0031-0034.0011. Published online.

Velasco, R., Zharkikh, A., Troggio, M., Cartwright, D. A., Cestaro, A.,
Pruss, D., Pindo, M., Fitzgerald, L. M., Vezzulli, S., Reid, J., Malacarne, G., Iliev, D., Coppola, G., Wardell, B., Micheletti, D., Macalma, T., Facci, M., Mitchell, J. T., Perazzolli, M., Eldredge, G., Gatto, P., Oyzerski, R., Moretto, M., Gutin, N., Stefanini, M., Chen, Y., Segala, C., Davenport, C., Dematte, L., Mraz, A., Battilana, J., Stormo, K., Costa, F., Tao, Q., Si-Ammour, A., Harkins, T., Lackey, A., Perbost, C., Taillon, B., Stella, A., Solovyev, V., Fawcett, J. A., Sterck, L., Vandepoele, K., Grando, S. M., Toppo, S., Moser, C., Lanchbury, J., Bogden, R., Skolnick, M., Sgaramella, V., Bhatnagar, S. K., Fontana, P., Gutin, A., Van de Peer, Y., Salamini, F., and Viola, R. 2007. A high quality draft consensus sequence of the genome of a heterozygous grapevine variety. PLoS One 2:e1326.

Waterhouse, A. M., Procter, J. B., Martin, D. M., Clamp, M., and Barton, G. J. 2009. Jalview Version 2-A multiple sequence alignment editor and analysis workbench. Bioinformatics 25:1189-1191.

Wu, J., Zhang, Y., Zhang, H., Huang, H., Folta, K. M., and Lu, J. 2010. Whole genome wide expression profiles of Vitis amurensis grape responding to downy mildew by using Solexa sequencing technology. BMC Plant Biol. 10:234.

Young, N. D., Debelle, F., Oldroyd, G. E., Geurts, R., Cannon, S. B., Udvardi, M. K., Benedito, V. A., Mayer, K. F., Gouzy, J., Schoof, H., Van de Peer, Y., Proost, S., Cook, D. R., Meyers, B. C., Spannagl, M., Cheung, F., De Mita, S., Krishnakumar, V., Gundlach, H., Zhou, S., Mudge, J., Bharti, A. K., Murray, J. D., Naoumkina, M. A., Rosen, B., Silverstein, K. A., Tang, H., Rombauts, S., Zhao, P. X., Zhou, P., Barbe, V., Bardou, P., Bechner, M., Bellec, A., Berger, A., Berges, H., Bidwell, S., Bisseling, T., Choisne, N., Couloux, A., Denny, R., Deshpande, S., Dai, X., Doyle, J. J., Dudez, A. M., Farmer, A. D., Fouteau, S., Franken, C., Gibelin, C., Gish, J., Goldstein, S., Gonzalez, A. J., Green, P. J., Hallab, A., Hartog, M., Hua, A., Humphray, S. J., Jeong, D. H., Jing, Y. Jocker, A., Kenton, S. M., Kim, D. J., Klee, K., Lai, H., Lang, C., Lin, S., Macmil, S. L., Magdelenat, G., Matthews, L., McCorrison, J., Monaghan, E. L., Mun, J. H., Najar, F. Z., Nicholson, C., Noirot, C., O’Bleness, M., Paule, C. R., Poulain, J., Prion, F., Qin, B., Qu, C., Retzel, E. F., Riddle, C., Sallet, E., Samain, S., Samson, N., Sanders, I., Saurat, O., Scarpelli, C., Schiex, T., Segurens, B., Severin, A. J., Sherrier, D. J., Shi, R., Sims, S., Singer, S. R., Sinharoy, S., Sterck, L., Viollet, A., Wang, B. B., Wang, K., Wang, M., Wang, X., Warfsmann, J., Weissenbach, J., White, D. D., White, J. D., Wiley, G. B., Wincker, P., Xing, Y., Yang, L., Yao, Z., Ying, F., Zhai, J., Zhou, L., Zuber, A., Denarie, J., Dixon, R. A., May, G. D., Schwartz, D. C., Rogers, J., Quetier, F., Town, C. D., and Roe, B. A. 2011. The Medicago genome provides insight into the evolution of rhizobial symbioses. Nature 480:520-524.

Zhu, S., Gao, B., and Tytgat, J. 2005. Phylogenetic distribution, functional epitopes and evolution of the CS $\alpha \beta$ superfamily. Pages 2257-2269 in: Cellular and Molecular Life Sciences, Vol. 62. Birkhäuser Verlag, Basel, Switzerland.

Zimmerli, L., Stein, M., Lipka, V., Schulze-Lefert, P., and Somerville, S. 2004. Host and non-host pathogens elicit different jasmonate/ethylene responses in Arabidopsis. Plant J. 40:633-646.

\section{AUTHOR-RECOMMENDED INTERNET RESOURCES}

Computational Biology Web Resources website: genomics.research.iasma.it/\#

ExPASy Theoretical Molecular Mass and Isoelectric Point calculator: web.expasy.org/compute_pi

GeneSplicer Web Interface: www.cbcb.umd.edu/software/GeneSplicer/gene_spl.shtml

Genoscope Vitis vinifera webpage: www.genoscope.cns.fr/spip/Vitis-vinifera-e 